\title{
Entidades y «entes» de ámbito territorial inferior al municipio tras la reforma local de $2013^{1}$
}

\author{
Entities and «bodies» of territorial scope inferior to the municipality \\ after the local reform of 2013
}

\author{
Rafael Pizarro Nevado \\ Universidad de Córdoba \\ rpizarro@uco.es
}

\begin{abstract}
RESUMEN
La Ley 27/2013, de 27 de diciembre, de racionalización y sostenibilidad de la Administración Local (LRSAL), reformó profundamente la legislación básica sobre entidades de ámbito territorial inferior al municipio para adecuarla a los principios de eficiencia, estabilidad presupuestaria y sostenibilidad financiera. Esa regulación, junto con otros preceptos de la LRSAL, fue objeto de numerosos recursos de inconstitucionalidad. Durante el último año el Tribunal Constitucional ha resuelto la mayor parte de esos recursos, por lo que es oportuno determinar qué repercusión ha tenido finalmente la LRSAL en la legislación autonómica sobre entidades inframunicipales y cuáles son las alternativas que se ofrecen a las poblaciones separadas que aspiren a disfrutar de una mayor y más directa implicación en el gobierno de los intereses de sus vecinos. Para ello se expone en primer lugar la doctrina constitucional sobre la competencia estatal para regular sobre este tipo de entidades, el alcance de la reforma y las opciones que se abren ante el legislador autonómico. Posteriormente se analizan los preceptos de carácter básico que específicamente se refieren a las dos soluciones organizativas previstas en la LRSAL, las tradicionales entidades de ámbito territorial inferior al municipio, que conservan su personalidad jurídica y su condición de entidades locales, y los nuevos órganos municipales desconcentrados, impropiamente llamados «entes de ámbito territorial inferior al municipio».
\end{abstract}

\section{PALABRAS CLAVE}

Descentralización, desconcentración, entidades inframunicipales, organización municipal, régimen local.

\begin{abstract}
Act 27/2013, of 27 December, on rationalization and sustainability of Local Administrations, deeply reformed the basic legislation on entities of territorial scope inferior to the municipality to adapt it to the principles of efficiency, budgetary stability and financial sustainability. This regulation was appealed before the Constitutional Court, which has resolved most of the appeals filed. Therefore it is convenient to determine which impact has Act 27/2013 finally had in the Autonomous Communities legislation on infra-municipal entities and which are the alternatives offered to little settlements that aspire to a greater and more direct participation in the government of the interests of its population. For this purpose, the constitutional doctrine on the state competence to regulate this type of entities, the scope of the reform and the options that are opened before the autonomous legislator are exposed first. Subsequently, the basic precepts that specifically refer to the traditional entities of territorial scope inferior to the municipality, which retain their legal personality and their status as local entities, and the new deconcentrated municipal bodies are analysed.
\end{abstract}

\section{KEYWORDS}

Decentralization, deconcentration, infra-municipal entities, organization of the municipality, local regime.

1 Esta investigación se ha desarrollado en el seno del Grupo de Investigación de la Junta de Andalucía SEJ-196 en la Universidad de Córdoba. Proyecto de Investigación del Ministerio de Economía y Competitividad DER 2015/67685. 
REALA. Nueva Época - N. 8, noviembre 2017 - ISSN: 1989-8975 - DOI: 10.24965/reala.v0i8.10437 - [Págs. 49-73]

Entidades y «entes» de ámbito territorial inferior al municipio tras la reforma local de 2013

Rafael Pizarro Nevado

\begin{abstract}
SUMARIO
I. ALTERNATIVAS PARA EL GOBIERNO DE LOS PUEBLOS SEPARADOS DE LA CAPITALIDAD MUNICIPAL. II. TRATAMIENTO DE LOS PEQUEÑOS NÚCLEOS DE POBLACIÓN EN LA REFORMA LOCAL DE 2013. 1. EL RECHAZO POLÍTICO Y DOCTRINAL DE LA REFORMA LOCAL DE 2013. 2. EXTENSIÓN DE LA COMPETENCIA ESTATAL PARA LEGISLAR SOBRE ENTIDADES INFRAMUNICIPALES DESCENTRALIZADAS. CONSTITUCIONALIDAD DE LA PROHIBICIÓN DE CREAR NUEVAS ENTIDADES DE ESTE TIPO. 3. DE LA CONTRADICCIÓN SOBREVENIDA ENTRE LA LEGISLACIÓN BÁSICA ESTATAL Y LOS ESTATUTOS DE AUTONOMÍA Y SUS EFECTOS SOBRE LA LEGISLACIÓN AUTONÓMICA DE RÉGIMEN LOCAL. 4. EL RÉGIMEN ESPECIAL DE NAVARRA. 5. EL RÉGIMEN ESPECIAL DEL PAÍS VASCO. III. LAS ENTIDADES DE ÁMBITO TERRITORIAL INFERIOR AL MUNICIPIO TRAS LA LRSAL. 1. LA SUPRESIÓN DEL ARTÍCULO 45 LBRL Y LA SUBSISTENCIA DE LAS ENTIDADES INFRAMUNICIPALES EXISTENTES. 2. LAS NUEVAS CAUSAS DE DISOLUCIÓN DE ENTIDADES DE ÁMBITO TERRITORIAL INFERIOR AL MUNICIPIO. a) Disolución por incumplimiento del deber de presentación de cuentas. b) Disolución por exigencia de un plan económico-financiero. 3. RÉGIMEN APLICABLE A LAS ENTIDADES EN PROCESO DE CONSTITUCIÓN. IV. EL RÉGIMEN BÁSICO DE LOS NUEVOS ÓRGANOS DESCONCENTRADOS. 1. DENOMINACIÓN Y NATURALEZA JURÍDICA. 2. PROCEDIMIENTO DE CREACIÓN, MODIFICACIÓN Y SUPRESIÓN. 3. COMPETENCIAS, ORGANIZACIÓN Y FUNCIONAMIENTO. V. CONSIDERACIONES FINALES. REFERENCIAS BIBLIOGRÁFICAS.
\end{abstract}

La Ley $27 / 2013$, de 27 de diciembre, de racionalización y sostenibilidad de la Administración Local (LR$\mathrm{SAL}$ ), ha reformado profundamente la legislación básica de régimen local, y lo hizo ante todo para asegurar la sujeción de los gobiernos locales a los principios de estabilidad presupuestaria y sostenibilidad financiera, por lo que fue fuertemente contestada por Comunidades Autónomas y las propias Entidades Locales, que criticaron lo que consideraban una excesiva atención a objetivos financieros y el olvido de muchas reformas largamente demandadas por el mundo local. Además, cuestionaron la constitucionalidad de muchas de sus previsiones, por lo que se interpusieron hasta once recursos ante el Tribunal Constitucional. Durante el último año este ha dictado nueve sentencias que resuelven la mayor parte de los recursos de inconstitucionalidad planteados y declaran la conformidad con el Texto Fundamental de buena parte del contenido de la LRSAL. Pero también se han anulado por vulnerar el Texto Fundamental preceptos centrales para los objetivos de la reforma local, y la constitucionalidad de otros se ha salvado imponiendo una determinada interpretación conforme a la Constitución. Es el momento, por tanto, de analizar cómo queda finalmente configurado el régimen local tras esos pronunciamientos, y debe hacerse atendiendo a las distintas instituciones afectadas ${ }^{2}$.

Ese es el objetivo de este artículo en relación con las entidades de ámbito territorial inferior al municipio, a las que esa jurisprudencia presta especial atención. Es el momento de determinar cuál ha sido la repercusión real de la LRSAL en la legislación autonómica sobre entidades inframunicipales, que en la mayor parte de los casos no se ha adaptado a la nueva legislación básica, y cuáles son las opciones que se ofrecen a las poblaciones separadas que aspiren a disfrutar de una mayor y más directa implicación en el gobierno de los intereses de sus vecinos.

\title{
I. ALTERNATIVAS PARA EL GOBIERNO DE LOS PUEBLOS SEPARADOS DE LA CAPITALIDAD MUNICIPAL
}

Afirmaba MAURA que España es un país de pueblos, de pequeños municipios, pero también de aldeas, villas y caseríos. A pesar del tiempo transcurrido la frase aún refleja la importancia que en el mundo rural tienen esas pequeñas comunidades, que nunca alcanzaron la condición de municipio, pero que son titulares de intereses propios, muchas veces contrapuestos a los municipales. El camino recorrido por esos asentamientos para encontrar cauces de expresión colectiva y de gobierno de sus intereses ha sido azaroso y en muchas ocasiones se desarrolló de espaldas a la legislación, lo que explica la variedad de situaciones resultante y el apego a la tradición en muchas de estas poblaciones ${ }^{3}$.

2 Del alcance de las sentencias se han ocupado BOIX PALOP, Andrés (2017): "EI régimen local tras el fracaso de la reforma 2013", El cronista del Estado Social y Democrático de Derecho, 68: 24-35; MEDINA ALCOZ, Luis (2017): "La distribución de competencias entre el Estado y las comunidades autónomas a la luz de las sentencias constitucionales sobre la reforma local de 2013", Anuario del Gobierno Local 2015/2016. Barcelona: Fundación Democracia y Gobierno Local - Instituto de Derecho Público.

${ }_{3}^{3}$ Sobre la evolución del régimen jurídico de los distintos asentamientos rurales vid. ROSA MORENO, Juan (1991): "Aproximación histórica a la articulación orgánica de los núcleos separados de población”, Revista de Estudios Locales y Autonómicos, 262: 219-246; 
Hasta bien entrado el siglo XIX esos pequeños poblados asumieron normalmente la condición de aldeas dependientes de una villa o la de arrabal de las ciudades. Una tercera forma de organización agrupaba minúsculas poblaciones organizadas como corporaciones cerradas o ayuntamientos. Cada uno de estos pueblos constituía una unidad administrativa que respondía al nombre de concejo (o parroquia en Asturias y Galicia). En ese caso los ayuntamientos se integraban por una agrupación de concejos.

La situación no cambió sustancialmente durante los primeros años del constitucionalismo decimonónico, porque el proceso de creación de nuevos ayuntamientos al amparo de las previsiones de la Constitución de 1812 fue rápidamente abortado con la vuelta al absolutismo ${ }^{4}$. Por tanto, durante el siglo XIX, al margen del municipio, para el gobierno de esos pueblos únicamente se admitía la creación de órganos desconcentrados $^{5}$. Hasta el Estatuto Municipal de 1924 no se permitió que los núcleos de población que hasta ese momento eran simples barrios o pueblos agregados se constituyeran como entidades locales menores con personalidad jurídica propia y los caracteres con los que hoy se las conoce ${ }^{6}$.

Lógicamente no todos los pueblos alcanzaron la condición de municipio o de entidad local menor. Muchos continuaron siendo simples órganos municipales desconcentrados y otros muchos siguieron sin articulación orgánica alguna. Pero con el Estatuto Municipal se inició un proceso descentralizador que se mantuvo durante la II República ${ }^{7}$ y la dictadura, aunque durante esa etapa las entidades locales menores estuvieron completamente supeditadas al municipio ${ }^{8}$.

Esa situación cambia radicalmente con la promulgación de la Ley 7/1985, de 2 de abril, Reguladora de las Bases del Régimen Local ${ }^{9}$ (LBRL) y, sobre todo, de la legislación autonómica sobre entidades de ámbito territorial inferior al municipio ${ }^{10}$, que en desarrollo del principio constitucional de descentralización territorial

ORDUÑA REBOLLO, Enrique (2000): "Las entidades de ámbito territorial inferior al municipio. Del pasado al futuro", en SOSA WAGNER, Francisco (coord.): El Derecho Administrativo en el umbral del siglo XXI. Homenaje al Dr. D. Ramón Martín Mateo, Tomo I: 745772. Valencia: Tirant lo Blanch; o PIZARRO NEVADO, Rafael (2002), Las entidades de ámbito territorial inferior al municipio. Granada: $\mathrm{CEMCl}$. Específicamente en relación con los asentamientos gallegos vid. FARIÑA JAMARDO, José (1981): La parroquia rural en Galicia, 2. ${ }^{a}$ edición. Madrid; CASTRO BERMEJO, Cristina (1998): "Marco jurídico de la parroquia rural en Galicia", Revista de Estudios de la Administración Local y Autonómica, 276: 179-202; o MíGUEZ MACHO, Luis (2013): "Galicia y la reforma de la Administración local", Dereito: Revista xuridica da Universidade de Santiago de Compostela, núm. extra 1, 319-336.

${ }_{4}^{4}$ Aunque esa previsión constitucional fue desarrollada por los Decretos de 23 de mayo y de 10 de junio de 1812, el proceso iniciado fue pronto bloqueado con la restauración del absolutismo. Por Real Cédula de 30 de julio de 1814 se ordenó la disolución de los ayuntamientos constitucionales y se restablecieron los ayuntamientos, corregidores y alcaldes mayores en la planta que tenían en 1808. Vid. ORDUÑA REBOLLO (2000: 746) o PIZARRO NEVADO (2002: 31).

5 TOLIVAR ALAS (2014: 372) recuerda que la Ley Local de 1823 instituyó la figura del celador como órgano desconcentrado en barrios, aldeas, lugares o caseríos. La Ley Municipal de 1845 contemplaba la existencia de un Alcalde pedáneo «cuando el distrito de un Ayuntamiento se componga de varias parroquias, feligresías o poblaciones apartadas entre sí [ $\cdots]$ excepto el caso de que en la misma resida alguno de los Tenientes». La Ley Municipal de 1870 reguló la figura de los pueblos agregados, para cuya administración se preveía la constitución de una Junta compuesta por un Presidente y dos o cuatro vocales elegidos por los vecinos de entre ellos mismos

${ }^{6}$ El artículo 4 del Estatuto Municipal disponía que el Ayuntamiento o la Junta Vecinal tenían plena capacidad «para adquirir, reivindicar, conservar o enajenar bienes de toda clase, celebrar contratos, establecer y explotar obras y servicios públicos, obligarse y ejercitar acciones civiles, criminales, administrativas o contencioso-administrativas en nombre de los Municipios y Entidades locales menores respectivamente». Por su parte, el artículo 191 establecía que la «Junta vecinal o parroquial tendrá personalidad en nombre de la respectiva entidad, para aprobar Ordenanzas, interponer acciones judiciales de todo género, promover procedimientos administrativos y económico-administrativos, conservar el patrimonio comunal persiguiendo a los detentadores o usurpadores del mismo, y cuidar de la policía de los caminos rurales y vecinales, fuentes, ríos y montes, con arreglo a lo que dispongan las leyes». Cada entidad tenía un Alcalde pedáneo y una Junta Vecinal de base representativa. El artículo 97 señalaba que los vecinos del respectivo lugar eran los únicos electores y elegibles para los cargos de las Juntas, «sin excluir entre los electores a las mujeres cabeza de familia, cuando su intervención sea tradicional». Estas juntas vecinales funcionaban de forma análoga a las juntas municipales de los ayuntamientos. Además, las entidades cuya población no excedía de 1.000 habitantes se gobernaban en régimen de concejo abierto. Vid. COSCULLUELA MONTANER, Luis (1978): voz «Junta Vecinal», en Nueva Enciclopedia Jurídica Seix, XIV: 296.

7 La Ley municipal catalana de 14 de agosto de 1933 reconoció a las corporaciones municipales la competencia para crear entidades autónomas submunicipales y la Ley Municipal de 1935 reguló las entidades locales menores con «plena capacidad jurídica dentro de los límites y con los requisitos establecidos en las leyes».

${ }^{8}$ Aunque esa subordinación no permitía considerarlas realmente autónomas, lo cierto es que conservaron su personalidad jurídica. Además, se reguló la creación de nuevas entidades locales menores en la legislación de régimen local y en la que ordenaba las políticas de colonización. Vid. PIZARRO NEVADO (2002: 42-46) o MENÉNDEZ GARCÍA, Pablo (2003): "Las entidades de ámbito territorial inferior al municipio", en MUÑOZ MACHADO, Santiago (dir.): Tratado de Derecho Municipal, Tomo I: 1183. Madrid: Civitas.

9 Vid. PIZARRO NEVADO (2002: 65-70); y PIZARRO NEVADO, Rafael (2007): "Comentario al artículo 45 LBRL", en REBOLLO PUIG, Manuel (dir.): Comentarios a la Ley Reguladora de las Bases de Régimen Local: 1.053-1.087. Valencia: Tirant lo Blanch.

10 De todas las entidades reguladas en el LBRL, eran las entidades de ámbito territorial inferior al municipio las que admitían mayor diversificación, puesto que, a pesar de que el artículo 45 LBRL contenía algunas reglas indisponibles, se dejaba en manos de las Comunidades Autónomas una amplísima libertad para determinar la mayoría de los aspectos de su régimen jurídico. En realidad, la 
las configuraron como entidades locales completamente diferenciadas de la municipal, con personalidad jurídica propia y plena capacidad para el cumplimiento de sus fines. Y no solo se reforzó su autonomía, porque a la vista del amplio margen de actuación que permitía en este ámbito la legislación básica, las leyes autonómicas rompieron el modelo uniforme existente hasta entonces para atender a la pluralidad de situaciones sociológicas y económicas que salpicaban la geografía española, reconociendo las singularidades de los distintos tipos de asentamientos y otorgando un tratamiento específico a cada uno de ellos ${ }^{11}$.

Para aquellos núcleos de población que no llegaron a constituirse ni en pequeños municipios ni en entidades locales menores, y para los que se han formado durante las últimas décadas, la legislación vigente también ofrece distintas fórmulas de administración desconcentrada concebidas para canalizar la voluntad de participación de sus vecinos en el gobierno local y la gestión de sus intereses comunes ${ }^{12}$.

Baste este rápido recorrido para comprobar que la evolución del tratamiento jurídico de los pequeños asentamientos, plagada de avances y retrocesos alternativos, refleja la tensión permanente entre la voluntad de esas pequeñas comunidades por participar en el gobierno de los que consideran sus asuntos y razones de índole organizativa, que apuestan por Administraciones de dimensiones adecuadas para satisfacer eficazmente los intereses públicos. Durante los dos últimos siglos coexistieron distintas soluciones organizativas para los núcleos de población separados de la capitalidad municipal, aunque la legislación autonómica ha potenciado sobre todo las soluciones descentralizadoras, alumbrando entidades inframunicipales que con denominaciones muy distintas constituyen la expresión de toda una población asentada en un territorio, de una comunidad política con intereses propios netamente diferenciados de los generales del municipio ${ }^{13}$.

\section{TRATAMIENTO DE LOS PEQUEÑOS NÚCLEOS DE POBLACIÓN EN LA REFORMA LOCAL DE 2013}

Esa era la orientación mantenida en la legislación local hasta la promulgación de la LRSAL, que modificó profundamente la LBRL. Además de endurecer los requisitos para la creación de nuevos municipios, la reforma incidió directamente sobre la regulación de las entidades de ámbito territorial inferior al municipio, congelando su número, aumentando los mecanismos de control por las restantes Administraciones territoriales y fijando nuevas causas de disolución. Por otra parte, se introdujo una nueva fórmula de organización desconcentrada, que a partir de ese momento debía ser la única vía por la que transitaran los núcleos de población que no hubieran alcanzado la condición de entidad local.

Para el mejor entendimiento de estas reformas es necesario explicar previamente cuáles eran los objetivos que inspiraban el anteproyecto de LRSAL, cómo se fueron diluyendo durante el procedimiento de elaboración del texto legal y el rechazo que provocó entre los responsables políticos locales y autonómicos. También se debe señalar que el texto resultante contiene numerosas deficiencias -muchas oportunamente destacadas por la doctrina especializada durante su tramitación parlamentaria- y que algunas de sus previsiones planteaban serias dudas de constitucionalidad. El Tribunal Constitucional admitió a trámite once recursos sobre la constitucionalidad de la $\operatorname{LRSAL}^{14}$, de los cuales nueve han sido resueltos en las sentencias 41/2016, de 3 de marzo; 111/2016, de 9 de junio; 168/2016, de 6 de octubre; 180/2016, de 20 de octubre;

\footnotetext{
LBRL ni siquiera imponía la existencia de este tipo de entidades en todas las Comunidades Autónomas; $y$, menos aún, el que, de existir, tuvieran el carácter de entidades locales territoriales (PIZARRO NEVADO, 2007: 1060).

11 TOLIVAR ALAS (2014: 376) explica como esa diversificación deriva incluso de los propios Estatutos de Autonomía, que, con el beneplácito del Tribunal Constitucional, han querido apartarse del modelo uniforme que imponía la legislación anterior para adaptar estas entidades a las peculiaridades de los asentamientos de sus territorios.

12 Vid. TRAYTER JIMÉNEZ, Joan Manuel (2007): "Comentario a los artículos 24 y 128 LBRL”, en REBOLLO PUIG, Manuel (dir.): Comentarios a la Ley Reguladora de las Bases de Régimen Local: 671-681. Valencia: Tirant lo Blanch; o GALINDO CALDÉS, Ramón Lluís (2014): La organización territorial en los municipios: los distritos. Granada: CEMCI-Diputación de Granada.

${ }_{13}$ Al menos así ha sido en el plano legislativo, porque en no pocas ocasiones se ha avanzado más terreno en la redacción de la norma que en su aplicación práctica. TOLIVAR ALAS (2014: 376) ha puesto de manifiesto, por ejemplo, las dificultades de aplicación en el Principado de Asturias de la Ley 11/1986, de 20 de noviembre, por la que se reconoce la personalidad jurídica de la parroquia rural. Sorprende que en Asturias, a pesar de existir 857 parroquias, solo 39 han conseguido la declaración de parroquias rurales al amparo de esa Ley. Y de ellas 32 eran previamente entidades locales menores.

${ }_{14}$ Fueron diez recursos de inconstitucionalidad formulados por los gobiernos de las Comunidades Autónomas de Andalucía, Cataluña y Canarias, por el Consejo de Gobierno del Principado de Asturias, por los parlamentos autonómicos de Extremadura, Cataluña y Andalucía, por el Parlamento Foral de Navarra, por el Defensor del Pueblo y por representantes de los Grupos Parlamentarios Socialista, IU, ICV-EUIA, CHA, La Izquierda Plural, UPyD y Mixto en el Congreso de los Diputados. También se planteó un conflicto en defensa de la autonomía local, suscrito por 2.393 municipios, contra diversos preceptos de la LRSAL. Este último ha sido resuelto por
} 
44/2017 y 45/2017, ambas de 27 de abril; 54/2017, de 11 de mayo; 93/2017, de 6 de julio y 101/2017, de 20 de julio. En todos los recursos resueltos se cuestionaba la regulación sobre entidades inframunicipales, pero el Tribunal Constitucional ha confirmado su constitucionalidad con una única salvedad ${ }^{15}$. Pero conviene detenerse en los razonamientos del Tribunal para entender el alcance de la competencia estatal para regular sobre este tipo de entidades, la extensión de la reforma y las posibilidades que se abren ante el legislador autonómico.

La STC 41/2016, que resuelve el recurso de inconstitucionalidad 1792-2014, interpuesto por la Asamblea de Extremadura en relación con diversos preceptos de la LRSAL, es sin duda la más relevante a nuestros efectos, pues se pronuncia sobre todos los preceptos que afectan a las entidades de ámbito territorial inferior al municipio y sobre la regulación de los nuevos órganos desconcentrados. Las sentencias posteriores se apoyan en su doctrina para desestimar impugnaciones sustancialmente idénticas ${ }^{16}$, pero también resuelven cuestiones nuevas que merecen atención. Por ejemplo, la STC 168/2016, que resuelve el recurso de inconstitucionalidad 1995-2014, interpuesto por el Consejo de Gobierno del Principado de Asturias, se ocupa de la contradicción sobrevenida entre la legislación básica estatal sobre entes inframunicipales y los Estatutos de Autonomía ${ }^{17}$; o la STC 180/2016, que resuelve el recurso de inconstitucionalidad 2001-2014, interpuesto por el Parlamento de Navarra, en la que se desarrolla ese aspecto considerando las particularidades sobre régimen local que se derivan del artículo 46 de la Ley Orgánica 13/1982, de 10 de agosto, de Reintegración y Amejoramiento del Régimen Foral de Navarra.

\section{El rechazo político y doctrinal de la reforma local de 2013}

Las reformas planteadas despertaron desde el primer momento un importante rechazo entre los responsables políticos locales y autonómicos, que las consideraban promovidas desde posiciones que no comprendían adecuadamente el mundo local y su organización administrativa, que, a pesar de compartir ciertas características con la estatal y la autonómica, también responde a exigencias propias que no se habrían considerado adecuadamente. Lo cierto es que la LRSAL contiene una serie de medidas homogeneizadoras y permanentes que parecen movidas exclusivamente por la exigencia de una rápida reducción del gasto público, lo que se quería conseguir, entre otras cosas, con la supresión de los entes y organismos locales que no cumpliesen determinados criterios económicos o financieros. Tan drástica consecuencia debía producirse además en plazos muy breves y sin entrar a considerar las peculiaridades que presentaran las distintas entidades por razones históricas, geográficas, sociales o económicas. También se reprochaba a la reforma que, urgida por las necesidades financieras, se dejaba pasar la ocasión de hacer una revisión en profundidad del régimen local español para dar respuesta a problemas que los actores locales llevaban años denunciado ${ }^{18}$.

la STC 107/2017, de 21 de septiembre, que, a pesar de su evidente interés, no será comentada porque en el conflicto en defensa de la autonomía local no se impugnaron los preceptos que regulan las entidades inframunicipales.

15 Solo ha anulado por inconstitucional la referencia contenida en la disposición transitoria 4. ${ }^{a}$ LRSAL al Decreto del Consejo de Gobierno de la Comunidad Autónoma como medio para disolver las entidades inframunicipales que no rindiesen cuentas ante el Estado o la Comunidad Autónoma respectiva.

16 Buena parte de los recursos planteados por la Junta de Andalucía, el Consejo de Gobierno del Principado de Asturias, más de cincuenta diputados, integrantes de distintos Grupos Parlamentarios, el Parlamento de Andalucía y el Parlamento de Cataluña impugnaban los mismos preceptos basándose en los mismos motivos que el recurso de inconstitucionalidad núm. 1792-2014, presentado por la Asamblea de Extremadura. Por ello, las SSTC 111/2016, 168/2016, 44/2017, 45/2017, 54/2017 y $101 / 2017$ los rechaza de plano, con una simple remisión a los fundamentos jurídicos de la STC 41/2016. Algo similar sucede con el recurso planteado por el Gobierno de Cataluña, que en lo que respecta a las entidades de ámbito territorial inferior al municipio es parcialmente desestimado en este punto en la STC 93/2017 por remisión a lo razonado en las SSTC 41/2016, 111/2016 y 54/2017. En este caso, el TC únicamente entra a analizar la impugnación de la disposición transitoria cuarta de la LRSL por motivos no planteados en los anteriores recursos.

17 Sobre esa cuestión vuelve el Tribunal en la sentencia 19/2017, de 2 de febrero de 2017, que resuelve el recurso de inconstitucionalidad núm. 2256-2016, interpuesto por el Presidente del Gobierno, contra el artículo 19, apartado 6, de la Ley del Parlamento de Cataluña 16/2015, de 21 de julio, de simplificación de la actividad administrativa de la Administración de la Generalitat y de los gobiernos locales de Cataluña y de impulso a la actividad económica, que modificó el artículo 79 del Decreto Legislativo 2/2003, de 28 de abril, aprobatorio del texto refundido de la Ley municipal y de régimen local de Cataluña.

18 FONT I LLOVET y GALÁN GALÁN (2014: 15) señalaron que «tanto la planificación como la ejecución de la reforma local se han pensado desde arriba. Dicho al contrario, no es una reforma que nazca desde abajo, fruto de las reivindicaciones del mundo local, de manera que finalmente lleguen a lo alto para ser recogidas por un legislador sensible a dichas peticiones. Antes al contrario: el diagnóstico de la situación y la selección de las medidas a adoptar son labores cruciales que han sido realizadas en la soledad del ministerio y, probablemente, por manos expertas en economía. Porque, como decimos, la reforma local no pretende resolver los problemas que padecen los gobiernos locales, sino los problemas que, al menos en parte, se cree que han sido generados por ellos. No debe extrañar, pues, que en el texto de la nueva ley no se ofrezca respuesta a las denuncias de todo tipo, sobre carencias y necesidades de la vida 
No es extraño, por tanto, que la aplicación de la LRSAL se haya encontrado con enormes resistencias por parte de los obligados a aplicarla ${ }^{19}$.

También un sector de la doctrina fue muy crítico con la forma en que se llevó a cabo la reforma, mediante una más de las muchas leyes-medida que la crisis financiera y fiscal ha provocado, marcadas todas ellas casi exclusivamente por preocupaciones de índole económica y coyuntural ${ }^{20}$. En este tipo de leyes la atención se centra inevitablemente en la consecución del objetivo que motiva la reforma y no se considera con el mismo interés el impacto que la nueva regulación pueda tener sobre la coherencia, los principios o los restantes objetivos del texto reformado. En este caso se modificaron parcialmente las dos leyes basilares del ordenamiento local, la Ley 7/1985, de 2 de abril, Reguladora de las Bases del Régimen Local y el Texto Refundido de la Ley Reguladora de las Haciendas Locales, con el propósito declarado de «racionalizar la estructura organizativa de la Administración local de acuerdo con los principios de eficiencia, estabilidad y sostenibilidad financiera, garantizar un control financiero y presupuestario más riguroso», aunque para ello hayan sufrido, entre otros, los principios de descentralización y de proximidad de la gestión administrativa a los ciudadanos. Es muy significativo que al enumerar los principios que deben inspirar al legislador sectorial se haya sustituido la referencia a la «máxima proximidad de la gestión administrativa a los ciudadanos» por una simple mención a la «proximidad» junto a los principios de eficacia y eficiencia (artículo $2.1 \mathrm{LBRL}$ ); todo ello, además, con «estricta sujeción a la normativa de estabilidad presupuestaria y sostenibilidad financiera ${ }^{21}$. Queda así de manifiesto la posición que adopta el legislador básico y permite adelantar el tratamiento que van a tener los pequeños municipios y las entidades inframunicipales, seguramente porque se toma una visión muy plana sobre lo que son estas últimas.

Súmese a todo ello que las medidas incluidas en la primera redacción del anteproyecto de Ley fueron profundamente modificadas antes de su aprobación por el Consejo de Ministros, y que la poda continuó durante su tramitación parlamentaria ${ }^{22}$, suprimiendo alguna de las medidas más radicales y suavizando en buena medida las restantes, por lo que el resultado final ni podía satisfacer a los impulsores de la reforma, ni iba a ser aceptado por quienes se oponían a ella.

La LRSAL también mereció un juicio negativo por sus deficiencias técnicas ${ }^{23}$. La Ley arrastraba esas carencias desde su origen, lo que llevó al Consejo de Estado a denunciar en su dictamen sobre el ante-

local, que, desde hace largo tiempo, vienen haciéndose desde la doctrina y, sobre todo, desde las asociaciones representativas de entes locales. Sencillamente no es el objeto de la ley: no es el propósito de la reforma».

19 Vid. GALÁN GALÁN, Alfredo (2015): "La aplicación autonómica de la Ley de Racionalización y Sostenibilidad de la Administración Local", Revista de Estudios de la Administración Local y Autonómica: Nueva Época, núm. extra 1; o TEJEDOR BIELSA, Julio (2015): "El desarrollo autonómico de la reforma local de 2013. Entre la rebelión y el pragmatismo", en BOIX PALOP, Andrés y DE LA ENCARNACIÓN, Ana María (coord.): Los retos del gobierno local tras la reforma de 2013: 81-100. Cizur Menor (Navarra): Thomson Reuters-Aranzadi.

20 ALMEIDA CERREDA (2015: 43) afirma que la LRSAL es un claro ejemplo del llamado Derecho de la crisis económica, que lleva a implantar con carácter permanente soluciones movidas por una exigencia de ahorro inmediato de recursos públicos, pero que viene a modificar profundamente la legislación de régimen local sin una reconsideración sosegada de las bases de dicho sistema legal. Por su parte, VELASCO CABALLERO (2013a) destacó oportunamente que la absorción del Ministerio de Administraciones Públicas por el de Hacienda no ha sido neutra, porque ha desplazado a un segundo plano las perspectivas constitucional, política y jurídica sobre los gobiernos locales. En el plano orgánico esto se reflejaría en el debilitamiento de los órganos específicos sobre Administración Local, que no cuenta con una Dirección General, quedando estas cuestiones en cierto modo arrinconadas en una Subdirección General de Administración Local.

21 Vid. MELLADO RUIZ, Lorenzo (2014a): "Consecuencias derivadas de la supresión del principio de mayor proximidad”, El Consultor de los Ayuntamientos y de los Juzgados, 5.

22 Sobre la tramitación del anteproyecto vid. BOIX PALOP, Andrés (2014) y TOLIVAR ALAS, Leopoldo (2014: 390-396).

23 De ello se trató en la ponencia y las intervenciones posteriores sobre "La planta del gobierno local" que tuvo lugar en el VIII Congreso de Profesores de Derecho Administrativo, celebrado en la Universidad de Alicante los días 8 y 9 de febrero de 2013 , recogidas posteriormente en el libro La planta del gobierno local: actas del VIII Congreso de la Asociación Española de Profesores de Derecho Administrativo, Barcelona: Fundación Democracia y Gobierno Local, 2013; y en DOMINGO ZABALLOS, Manuel José (coord., 2014): Reforma del Régimen Local. La Ley de Racionalización y Sostenibilidad de la Administración Local: veintitrés estudios. Cizur Menor (Navarra): Thomson Reuters-Aranzadi; SANTAMARÍA PASTOR, Juan Alfonso (coord., 2014): La reforma de 2013 del régimen local español. Barcelona: Fundación Democracia y Gobierno Local; QUINTANA LÓPEZ, Tomás (dir.) y CASARES MARCOS, Ana Belén (coord., 2014): La reforma del régimen local. Valencia: Tirant lo Blanch; BOIX PALOP, Andrés y DE LA ENCARNACIÓN, Ana María (coord., 2015): Los retos del gobierno local tras la reforma de 2013: 81-100. Cizur Menor (Navarra): Thomson Reuters-Aranzadi. También debe tenerse en cuenta el Anuario del Gobierno Local: ¿Un nuevo gobierno local en España? La reforma de la Administración local en la Ley 27/2013 y el número de Cuadernos de Derecho Local dedicado a: La revisión del Gobierno y la Administración local en la Ley 27/2013, 34 (2014). Cfr. también CARBONELL PORRAS, Eloísa (2014): "Sobre la reforma local y las competencias municipales propias", Revista Vasca de Administración Pública, núm. especial 99-100: 765-781; o FONT i LLOVET, Tomás y GALÁN GALÁN, Alfredo (2013), «Racionalización y sostenibilidad de la Administración local: ¿es ésta la reforma?» Anuario del Gobierno Local 2012, Barcelona: Fundación Democracia y Gobierno Local - Instituto de Derecho Público. 
proyecto la existencia de «cierta confusión conceptual» y a recomendar que se revisase «la redacción del anteproyecto para asegurar un adecuado empleo» de algunos términos. También proponía la rectificación de varias de las medidas propuestas en el anteproyecto para garantizar una mayor seguridad jurídica y una mejor articulación del texto resultante en el entramado constitucional de distribución de competencias, en particular la restrictiva regulación que se hacía sobre mancomunidades y entidades locales menores, que el Tribunal Constitucional había considerado organizaciones expresivas de la autonomía organizativa municipal y de alta interiorización autonómica. A pesar de que durante la tramitación parlamentaria se enmendó parcialmente el proyecto de ley, el texto finalmente aprobado seguía siendo deficiente y, consecuentemente, los textos legales que reformaba (LBRL y TRLRHL) y también la propia LRSAL -en aquellos preceptos que eran de aplicación directa- resultan confusos en bastantes extremos, cuando no contradictorios. Si además se considera que parte de su articulado ha sido declarado inconstitucional y que el Tribunal Constitucional ha impuesto una determinada interpretación «conforme a la Constitución» para otros preceptos (SSTC 41/2016, 111/2016, 168/2016 y 180/2016), se adivina que su aplicación va a ser dificultosa ${ }^{24}$.

El tratamiento dado a las entidades de ámbito territorial inferior al municipio es un buen ejemplo de todo lo anterior. Uno de los objetivos declarados del anteproyecto de LRSAL era la racionalización de la estructura organizativa de la Administración local de acuerdo con los principios de eficiencia, estabilidad presupuestaria y sostenibilidad financiera; entre las medidas previstas para lograrlo se encontraba una nueva regulación de las entidades de ámbito territorial inferior al municipio en la que se las privaba de su personalidad jurídica. Pero en los continuos cambios que sufrió el texto durante el proceso de elaboración puede apreciarse cómo fue perdiendo importancia el objetivo racionalizador para al final atender casi en exclusiva al de sostenibilidad financiera (MELLADO RUIZ, 2014b: 27). Pronto se abandonó, por ejemplo, la idea de reformar la planta local mediante la supresión forzosa de municipios y se indultó a las entidades de ámbito territorial inferior al municipio, aunque en la primera versión del anteproyecto de LRSAL se proponía su completa desaparición. En una versión posterior, la que fue remitida para ser informada por el Consejo de Estado, ya estaba previsto mantener las entidades inframunicipales existentes, aunque se había añadido una disposición que supeditaba su supervivencia a la superación de un control de eficacia: se estuvo valorando concederles un plazo de tres meses para que presentaran sus cuentas y a continuación evaluar los servicios que prestasen, todo ello con la amenaza de disolución, si de la evaluación se deducía una inadecuada prestación de los servicios ${ }^{25}$. También estas previsiones sufrieron importantes modificaciones durante la tramitación parlamentaria del proyecto de ley, como se expondrá en los siguientes apartados.

Al final, las entidades de ámbito territorial inferior al municipio existentes en el momento de la entrada en vigor de la LRSAL han conservado su personalidad jurídica y la condición de entidad local (disposición transitoria cuarta), aunque su régimen jurídico ha sufrido una drástica modificación ${ }^{26}$. De hecho, con la sorprendente excepción del artículo 4, en la redacción vigente de la LBRL no se alude a la existencia de entidades inframunicipales con personalidad jurídica, porque se ha dejado sin contenido el artículo 45 LBRL y se ha suprimido la mención que se hacía en el artículo 3.2.a) LBRL a las «Entidades de ámbito territorial inferior al municipal, instituidas o reconocidas por las Comunidades Autónomas, conforme al artículo 45 de esta Ley». Además, se ha introducido el artículo 24 bis, en el que se regulan unos nuevos «entes [sic] de ámbito territorial inferior al municipio» como forma de gestión municipal desconcentrada y, por tanto, sin personalidad jurídica propia. El resultado final supone la coexistencia de dos fórmulas organizativas radicalmente distintas, puesto que mientras las tradicionales entidades locales menores siguen existiendo como entes descentralizados, las iniciativas que en el futuro se planteen para responder a las exigencias de participación en los asuntos de interés propio de los núcleos de población separados solo pueden canalizarse a través de órganos municipales desconcentrados.

24 GALÁN GALÁN (2015) ha analizado las dificultades para la aplicación de la LRSAL señalando como causas las importantes dudas interpretativas, la falta de previsión en la LRSAL de un adecuado régimen transitorio, su aplicación territorial diferenciada y el rechazo generalizado que ha causado. Más recientemente BOIX PALOP (2017) ha descrito el fracaso de la reforma y esbozado posibles soluciones a los retos que deja pendientes.

25 Esto era lo previsto en la disposición adicional undécima del anteproyecto de 18 de febrero de 2013, que imponía la disolución de las entidades inframunicipales en las que, tras la correspondiente evaluación, se dedujese «la inadecuación de la prestación de servicios en su ámbito». El Dictamen del Consejo de Estado destacó la inseguridad jurídica que producía una regulación tan imprecisa y la posible vulneración de las competencias autonómicas, dado el fuerte grado de «interiorización» autonómica de este tipo de entidades (STC 214/1989) y la regla desapareció de las siguientes versiones del anteproyecto.

26 De la nueva regulación sobre entidades de ámbito territorial inferior al municipio se ocupan ALMEIDA CERREDA (2014: 13), TOLIVAR ALAS (2014: 381), VELASCO CABALLERO (2014b: 50-53) o GALÁN y GALINDO (2015). 


\section{Extensión de la competencia estatal para legislar sobre entidades inframunicipales descentralizadas. Constitucionalidad de la prohibición de crear nuevas entidades de este tipo}

La doctrina y el Consejo de Estado habían señalado que la restrictiva regulación sobre entidades de ámbito territorial inferior al municipio podía desbordar el ámbito de la legislación básica en esta materia, ya que el Tribunal Constitucional las consideraba organizaciones expresivas de la autonomía organizativa municipal y de alta interiorización autonómica ${ }^{27}$. Así lo entendieron también los promotores de los recursos contra la LRSAL, que argumentaron que limitaba injustificadamente la libertad autonómica de creación de entidades inframunicipales y vulneraba la doctrina constitucional formulada en las sentencias 179/1985 y 214/1989. Por ello impugnaron el nuevo artículo 24 bis LBRL y la disposición transitoria cuarta de la LRSAL, que preveía la disolución de las entidades locales de ámbito territorial inframunicipal si no presentaban sus cuentas ante el Estado o las Comunidades Autónomas antes de una fecha determinada.

Ahora interesa centrarse en el primero de los preceptos impugnados, el artículo 24 bis, que introduce en la LBRL la figura de los «entes de ámbito territorial inferior al municipio», en realidad órganos desconcentrados del municipio (apartado primero del artículo 24 bis), que solo podrían crearse tras constatar además que resultan «una opción más eficiente para la administración desconcentrada de núcleos de población separados de acuerdo con los principios previstos en la Ley Orgánica 2/2012, de 27 de abril, de Estabilidad Presupuestaria y Sostenibilidad Financiera» (apartado tercero). Conectando este precepto con la supresión del artículo 45 LBRL, concluían los recurrentes que las Comunidades Autónomas no podían regular sobre creación de nuevas entidades inframunicipales descentralizadas. Así lo entendió también desde el principio una parte de la doctrina, que asumió que después de la entrada en vigor de la LRSAL para la administración de núcleos de población separados solo cabía utilizar las formas de gestión desconcentrada del artículo 24 bis $^{28}$. Basándose en la literalidad del artículo 24 bis y de la regulación contenida en la LRSAL, que únicamente alude a las entidades ya constituidas, concluían que las Comunidades Autónomas no podían regular de forma diferente sobre este aspecto, ni aplicar la legislación autonómica vigente para crear nuevas entidades de ámbito territorial inferior al municipio, por lo que solo les quedaba la posibilidad de recurrir a fórmulas de gestión desconcentrada.

Para llegar a esa conclusión había que aceptar una premisa de cuya constitucionalidad dudaban, como era que el Estado podía imponer un modelo restrictivo de organización inframunicipal e impedir a las Comunidades Autónomas adoptar cualquier opción descentralizadora, a pesar de que desde su creación el Tribunal Constitucional les había reconocido una amplísima competencia normativa sobre organización local. Concretamente en relación con las entidades de ámbito territorial inferior al municipio afirmó el Tribunal en su sentencia 214/1989 que eran entidades con un fuerte grado de interiorización autonómica, por lo que el Estado debía quedar al margen en cuestiones tan relevantes como la determinación de sus competencias. Ese razonamiento no impide que el Estado legisle sobre entidades inframunicipales, pero sí podía hacer pensar que una ley estatal que prohibiese la creación de entidades inframunicipales de naturaleza descentralizada, con personalidad jurídica y competencias propias, reduciendo las opciones normativas autonómicas -y las de autoorganización municipal- únicamente a formas de organización territorial desconcentrada, iba más allá de lo que hasta ese momento el Tribunal había considerado bases del régimen jurídico de las Administraciones Locales.

El Tribunal Constitucional ha despejado esa duda en la sentencia 41/2016, declarando la constitucionalidad de la LRSAL en ese extremo. Aunque admite que la creación y regulación de entidades inframunicipales es una decisión que afecta a la autonomía municipal constitucionalmente garantizada, añade que la protección de intereses supraautonómicos puede justificar una regulación básica sobre ese particular. Recuerda el Tribunal que, respetando el espacio que corresponde a la legislación autonómica y a la autoorganización local, la legislación básica puede «identificar aquel núcleo del ordenamiento que requiere de elementos comunes 0 uniformes en función de los intereses generales a los que sirve el Estado» (STC 41/2016, FJ 5) ${ }^{29}$. A partir de ahí

${ }^{27}$ Y se proponían interpretaciones moduladoras del alcance de la nueva regulación. Vid. ALMEIDA CERREDA, Marcos (2014: 21-23) o VELASCO CABALLERO, Francisco (2013b: 111-113 y 2014c: 19-21).

28 Vid. AMENÓS ALAMO, Joan (2014), «El elemento territorial del municipio en la Ley 27/2013, de Racionalización y Sostenibilidad de la Administración Local», Anuario del Gobierno Local 2013: 51. Barcelona: Fundación Democracia y Gobierno Local - Instituto de Derecho Público; MEDINA GUERRERO, Manuel (2014), La reforma del régimen local: 86. Valencia: Tirant lo Blanch.

29 En anteriores pronunciamientos ya había mantenido que, aunque la constitución y determinación del régimen jurídico de estas entidades, de carácter puramente contingente o voluntario, depende de la normativa local y de la legislación de las Comunidades Autónomas, el Estado puede «establecer algunas reglas o previsiones al respecto» [SSTC 4/1981, FJ 6; y 214/1989, FJ 15 a)]. En la STC 214/1989 se admite el establecimiento de reglas básicas que atiendan a «intereses generales de alcance supraautonómico» [FJ 15 letras a) y b)]. Esto debe hacerse con el límite de que se regulen únicamente «aquellos aspectos que sean necesarios, sin quepa agotar todo el espacio normativo que debe corresponder al legislador autonómico, en especial en las cuestiones relacionadas con la organi- 
el Tribunal acepta que limitar la creación de nuevos entes descentralizados «condiciona la potestad municipal de autoorganización y las competencias autonómicas sobre régimen local», pero explica que «tal exigencia se inspira directamente en los mandatos constitucionales de eficiencia en el uso de los recursos públicos (artículo 31.2 CE) y estabilidad presupuestaria (artículo $135 \mathrm{CE}$ ), sin vulnerar por ello la potestad organizatoria municipal ni hurtar a las Comunidades Autónomas un amplio margen de desarrollo» ${ }^{30}$. Con esa vaga referencia se entiende cumplido el requisito exigido desde la STC 214/1989 [FJ 15 b)] de afectación de «intereses generales de alcance supraautonómico», por lo que declara el carácter de legislación básica de la prohibición de crear entidades inframunicipales descentralizadas y su conformidad con la garantía constitucional de la autonomía local.

Con este razonamiento el Tribunal Constitucional asume abiertamente la directriz que inspira la LRSAL, que -como se explica en la propia STC 41/2016- ha «cambiado el sentido político de su regulación en el marco del amplio margen de configuración que le asigna la Constitución», densificando el contenido la legislación básica estatal y reduciendo correlativamente las alternativas de regulación de las Comunidades Autónomas y la autonomía organizativa de las entidades locales para contener el número de personificaciones públicas ${ }^{31}$.

En cuanto a la regulación de los órganos desconcentrados contenida en el artículo 24 bis LBRL, también entiende el Tribunal Constitucional que se justifica en «intereses generales de alcance supraautonómico» y que deja «amplios espacios de desarrollo autonómico y autoorganización local» [FJ 15 b)], por lo que no aprecia tachas de inconstitucionalidad. A juicio del Tribunal, el legislador básico no habría «ocupado más espacio normativo» del que ocupaba antes de la reforma, restringiendo correlativamente las posibilidades de desarrollo por parte de las Comunidades Autónomas; simplemente habría «cambiado el sentido político de su regulación en el marco del amplio margen de configuración que le asigna la Constitución». También valora que el artículo 24 bis no contiene reglas precisas sobre creación, organización y competencias, por lo que para su aplicación resulta imprescindible que la regulación sea completada por la legislación autonómica y, en su caso, por las normas que establezcan los propios municipios. Por todo ello concluye que el precepto «se sitúa dentro de los márgenes del art. 149.1.18 CE».

En la STC 41/2016 solo se enjuició la constitucionalidad de los artículos 3.2 y 24 bis LBRL y de la disposición transitoria cuarta de la LRSAL (FJ 7 a), b) y c)), que fueron los impugnados por la Asamblea de Extremadura en el recurso de inconstitucionalidad 1792-2014. No lo fueron en ese momento el artículo 1.14 LRSAL, que deroga y deja sin contenido el artículo $45 \mathrm{LRBL}$, ni la disposición transitoria quinta de la LRSAL, que reconoce el carácter de entidad local con personalidad jurídica de las entidades inframunicipales ya constituidas y las que el 1 de enero de 2013 estaban en proceso de creación; pero si se incluyeron en el recurso de inconstitucionalidad 1996-2014, interpuesto por el Parlamento de Cataluña. En este segundo recurso el artículo 1.14 y la disposición transitoria quinta de la LRSAL se impugnaron en conexión con los artículos 3.2 y 24 bis LBRL y la disposición transitoria cuarta de la LRSAL y con el mismo argumento, que todo el conjunto normativo suponía un cambio sustancial del régimen básico de las entidades locales de ámbito inferior al municipio que vulneraba el artículo 87.2 EAC, conforme al que los núcleos separados de un municipio pueden constituirse en «entidades municipales descentralizadas», lo que permitió al Tribunal Constitucional confirmar su constitucionalidad en la STC 54/2017 (FJ 2 c) in fine) con una simple remisión a lo expuesto en el FJ 7 a), b) y c) de la STC 41/2016, sin necesidad de completar sus argumentos.

\section{De la contradicción sobrevenida entre la legislación básica estatal y los Estatutos de Autonomía y sus efectos sobre la legislación autonómica de régimen local}

Esa primera conclusión plantea otra cuestión de naturaleza constitucional, como es la necesidad de resolver la contradicción entre la legislación básica estatal y las previsiones de los Estatutos de Autonomía, ya que hay preceptos de la LRSAL que chocan frontalmente con algunos de ellos, como el artículo 86.7

zación y funcionamiento interno de los órganos» [STC 41/2016, FJ 5, que sintetiza la doctrina de las SSTC 32/1981, FJ 5; 214/1989, FJ 6; 50/1999, FJ 3 y 103/2013, FJ 5 e)].

${ }_{30}$ ALMEIDA CERREDA (2016: 242), duda que se pueda afirmar, en abstracto y con carácter general, que optar por la desconcentración frente a las tradicionales estructuras desconcentradas vaya a suponer automáticamente un aumento de la eficiencia en el uso de los recursos públicos y de la estabilidad presupuestaria, por el simple hecho de que el nuevo órgano desconcentrado esté sujeto jerárquicamente a los órganos de gobierno de los ayuntamientos.

${ }_{31}$ En el FJ 8 de la STC 41/2016 se afirma, en relación con la preferencia asignada en el artículo 57.3 LRSAL a la fórmula convencional sobre la consorcial, que «puede discutirse políticamente, pero constituye una directriz directamente encaminada a desarrollar una política de contención de personificaciones públicas que se sitúa dentro de los amplios márgenes de configuración legislativa que abre la Constitución y amparan los apartados 14 y 18 del art. 149.1 CE». 
del Estatuto de Autonomía de Cataluña, en el que se dispone que «las concentraciones de población que dentro de un municipio constituyan núcleos separados pueden constituirse en entidades municipales descentralizadas. La ley debe garantizarles la descentralización y la capacidad suficientes para llevar a cabo las actividades y prestar los servicios de su competencia». También entran en contradicción con el artículo 58 del Estatuto de Autonomía de Extremadura, que establece que «[p]or ley se regularán las formas de constitución, organización, competencias y régimen jurídico y financiero de las entidades locales menores, áreas metropolitanas, mancomunidades, consorcios y aquellas otras agrupaciones voluntarias o necesarias de municipios que pudieran establecerse, reconociendo, en todo caso, su autonomía administrativa y su personalidad jurídica»; y con los artículos 27.2 y 40.3 del Estatuto de Autonomía para Galicia, en el que se reconoce la competencia exclusiva de la Comunidad Autónoma para regular las «parroquias rurales como entidades locales propias de Galicia» y expresamente se les atribuye personalidad jurídica. Hasta la reforma de 2013 esos preceptos estatutarios no planteaban problema alguno, porque lo dispuesto en los Estatutos coincidía con lo previsto en la legislación estatal. Pero con la aprobación de la LRSAL, que impide la creación de nuevas entidades inframunicipales con personalidad jurídica, se produce una contradicción sobrevenida.

Sobre esta cuestión ha tenido ocasión de pronunciarse el Tribunal Constitucional en la sentencia 168/2016, de 6 de octubre, que resuelve el recurso de inconstitucionalidad 1995-2014, interpuesto por el Gobierno del Principado de Asturias en relación con diversos preceptos de la LRSAL. La recurrente alegaba, entre otras cosas, la vulneración del artículo 6.1 del Estatuto de Autonomía para Asturias, que reconoce expresamente la personalidad jurídica de las «parroquias rurales», que es como se denominan las entidades inframunicipales del Principado de Asturias. El Tribunal rechaza ese motivo recordando que en anteriores sentencias había declarado que el Estatuto, en tanto que norma institucional básica de la Comunidad Autónoma (artículo 147.1 CE), puede contener las «líneas fundamentales o la regulación esencial» del régimen local en su ámbito territorial, «pero solo con el fin de "vincular al legislador autonómico" y respetando "en todo caso la competencia básica que al Estado corresponde en la materia en virtud de la reserva del artículo 149.1.18 CE, por cuanto la expresión 'bases del régimen jurídico de las Administraciones públicas' engloba a las Administraciones locales"» ${ }^{32}$ [SSTC 41/2016, FJ 3 a); 31/2010, FFJJ 36 y 37; y 103/2013, FJ 4]. Entiende por tanto el Tribunal que «una norma estatutaria de régimen local no puede funcionar como límite al ejercicio de la competencia constitucionalmente atribuida al Estado en esta materia», ni «impedir de ninguna manera el ejercicio de esa competencia estatal» ${ }^{33}$ (STC 31/2010, FJ 37). Esto es, el Estatuto no puede erigirse en obstáculo que evite que las bases desplieguen su función de «mínimo común normativo» aplicable en todas las Comunidades Autónomas (SSTC 168/2016, FJ 3 b) y 45/2017, FJ 2 c)); en relación con este concreto asunto, no impide que el Estado reforme las bases en materia de régimen local para prohibir la creación de nuevas entidades inframunicipales con personalidad jurídica.

La cuestión se ha planteado en términos similares en el recurso de inconstitucionalidad núm. 2256-2016, interpuesto por el Presidente del Gobierno, contra el apartado 6 del artículo 19 de la Ley del Parlamento de Cataluña 16/2015, de 21 de julio, de simplificación de la actividad administrativa de la Administración de la Generalitat y de los gobiernos locales de Cataluña y de impulso a la actividad económica, que modificó el artículo 79 del Decreto Legislativo 2/2003, de 28 de abril, aprobatorio del texto refundido de la Ley municipal y de régimen local de Cataluña (TRLMRLC). Este último regulaba la constitución de entidades municipales descentralizadas y en 2015 se reformaron varias de las reglas del procedimiento de constitución. El recurso ha sido resuelto por sentencia 19/2017, aplicando precisamente la doctrina fijada por el Tribunal Constitucional en relación con el marco estatutario catalán para concluir que la legislación catalana de régimen local debe ajustarse al artículo 24 bis LBRL, que es una norma formal y materialmente básica, descartando que

32 El mismo razonamiento había sido utilizado en el FJ 12 de la STC 41/2016, que resuelve el recurso planteado por la Asamblea de Extremadura contra la LRSAL, pero no para desestimar las impugnaciones planteadas contra la regulación de las entidades de ámbito territorial inferior al municipio, sino las dirigidas contra la ordenación de las competencias municipales. BOIX PALOP (2014: 13) ya había destacado el cambio en el entendimiento del Tribunal Constitucional sobre la extensión de la competencia estatal en esta materia, advirtiendo de las «posibilidades de delimitación competencial que se reconocen de facto al Estado a partir de títulos competenciales generales y a partir de sus facultades para establecer normas básicas».

${ }_{33}$ La STC 31/2010 descartó que pudiera estimarse que el capítulo IV, "El Gobierno Local", del título II, del Estatuto de Autonomía de Cataluña (en la redacción dada por la Ley Orgánica 6/2006, de 19 de julio), «transgreda la reserva estatutaria ex art. 147.2 CE, ni que impida el ejercicio de la competencia estatal en la materia»; una regulación estatutaria de «líneas fundamentales» del régimen local autonómico puede adoptarse «con el fin de vincular al legislador autonómico» y respetando "en todo caso», "como es obvio», «la competencia básica que al Estado corresponde en la materia» (FJ 36). La STC 41/2016 volvió sobre esta doctrina al resolver la impugnación dirigida contra el nuevo régimen básico de las competencias municipales (arts. 7.4 y 25 LBRL, en la redacción dada por los apartados 3 y 8 del art. 1 de la Ley 27/2013), pero la conclusión del TC fue la misma. 
artículo 86.7 del Estatuto de Autonomía de Cataluña «desplace o impida el ejercicio de la competencia estatal en materia de bases de régimen local ex art. 149.1.18 CE» (FJ 5). Sin embargo, no se declara inconstitucional el precepto que reforma el artículo 79 TRLMRLC, al menos no en su totalidad, sirviéndose para ello de una interpretación conforme a la Constitución. Recuerda el Tribunal que en las sentencias 41/2016 y 168/2016 ya había declarado que las nuevas bases estatales solo afectan a la «subjetividad» de los entes inframunicipales -a su configuración subjetiva como entes «descentralizados» con personalidad jurídica propia-, de lo cual deduce que la reforma introducida con la Ley catalana $16 / 2015$ no es incompatible con las bases estatales porque no afectaría a la dimensión subjetiva de estos entes (FJ 6). Lógicamente este razonamiento le lleva a concluir que a partir de ese momento el procedimiento de constitución regulado en el apartado c) del artículo 79.1 TRLMRLC solo puede utilizarse como cauce para constituir los nuevos entes de ámbito territorial inferior al municipio en Cataluña, en el bien entendido de que son entes de naturaleza desconcentrada.

Pero lo más interesante de esta sentencia es que a la interpretación conforme a la Constitución se le añade la declaración de inconstitucionalidad de la denominación utilizada en el precepto impugnado, precisamente por resultar incompatible con esa interpretación, y la extensión de los efectos de esa declaración a otros apartados del artículo 79 del texto refundido que no habían sido formalmente impugnados. Se percata el Tribunal Constitucional de que en la nueva redacción del artículo 79 TRLMRLC se sigue utilizando el adjetivo «descentralizada» para referirse a la entidad que se crearía y que ese adjetivo «conlleva la caracterización subjetiva que ha devenido incompatible con las nuevas bases», por lo que se declara «inconstitucional y nula, por su contradicción con la base estatal, esa concreta referencia». Pero los efectos de la declaración no terminan ahí, ya que, aplicando el artículo 39.1 de la Ley Orgánica del Tribunal Constitucional, la declaración de inconstitucionalidad se extiende por conexión «al resto de referencias que a dicho vocablo se contienen en el art. 79 del Decreto Legislativo $2 / 2003 »^{34}$, por considerar que, «si bien no han sido formalmente recurridas por venir contenidas en la anterior redacción [‥] del Decreto Legislativo 2/2003 que no ha sido modificada, las citadas expresiones, que se ajustaban a la legislación básica anterior, han devenido incompatibles con la normativa básica estatal ahora en vigor». Y añade, para terminar de extraer consecuencias de la caracterización básica de este nuevo tipo de entes, que cualquier referencia contenida en el artículo 79 TRLMRLC «a las «entidades locales» o la «entidad local» ha de entenderse referida a los entes locales menores de naturaleza desconcentrada y sin personalidad jurídica a que alude el art. 24 bis LBRL, salvo en aquellos casos en los que sea de aplicación la disposición transitoria quinta de la Ley 27/2013 por tratarse de entes que iniciaron su proceso de constitución antes del 1 de enero de 2013».

\section{El régimen especial de Navarra}

Pero no es cierto que la regulación sobre entidades inframunicipales contenida en la LRSAL sea aplicable en todas las Comunidades Autónomas, puesto que la propia LRSAL incluye criterios de diferenciación, que en esta materia afectan a la Comunidad Foral de Navarra y a la Comunidad Autónoma del País Vasco ${ }^{35}$.

Con apoyo en la disposición adicional tercera de la LBRL se puede sostener que la Comunidad Foral de Navarra mantiene íntegra su competencia histórica para regular y crear nuevos concejos -que es como se denominan las entidades inframunicipales en esa Comunidad Autónoma- y que no son aplicables en su territorio las limitaciones que introduce la LRSAL en materia de entidades inframunicipales en cuanto se opongan al régimen que para su Administración Local establece el artículo 46 de la Ley Orgánica 13/1982, de 10 de agosto, de Reintegración y Amejoramiento del Régimen Foral de Navarra (LORAFNA). Así se declara en la STC 180/2016, que resuelve el recurso de inconstitucionalidad 2001-2014, interpuesto por el Parlamento de Navarra contra varios preceptos de la LRSAL. En relación con la cuestión que nos ocupa, planteaba la recurrente que «el art. 24 bis [de la LRSAL] alude directamente a los "concejos" que constituyen una institución tradicional de Navarra sometida al régimen jurídico foral y por tanto ante una materia que forma parte de la competencia histórica de Navarra prevista en el art. 46.1 a) LORAFNA, y que encuentra un

${ }^{34}$ Precisa el Tribunal que la declaración de inconstitucionalidad afectaría en concreto a los adjetivos contenidos en la rúbrica del precepto, en el encabezamiento del apartado 1 del mismo («descentralizadas»), en el texto de la letra d) del mismo apartado («descentralizada») y en el texto del apartado 2 del aludido precepto («descentralizada»).

${ }_{35}$ Sobre los efectos de la LRSAL en la Comunidad Foral de Navarra y la Comunidad Autónoma del País Vasco vid. RAZQUIN LIZARRAGA, Martín María (2014): "Reforma local y derechos históricos: Navarra y País Vasco", en DOMINGO ZABALLOS, Manuel José (coord.): Reforma del Régimen Local. La Ley de Racionalización y Sostenibilidad de la Administración Local: veintitrés estudios: 117150. Cizur Menor (Navarra): Thomson Reuters-Aranzadi; o VELASCO CABALLERO, Francisco (2014c). 
completo desarrollo en la Ley Foral de Administración local, en la sección primera del capítulo II, del título 1, arts. 37 a 44 , ya que el art. 37.1 reconoce expresamente como ámbitos territoriales inferiores al municipio y "con personalidad jurídica para la gestión y administración de sus intereses en el ámbito de las competencias atribuidas a los mismos por esta Ley Foral"» y, consecuentemente, limitaría de manera injustificada la competencia autonómica.

En este caso, aunque el Tribunal Constitucional mantiene su afirmación de que las disposiciones estatutarias en materia de régimen local condicionan solo al legislador autonómico y que no prevalecen frente a la legislación básica en caso de conflicto (STC 31/2010), explica que esa doctrina no es aplicable en el caso de Navarra. Entiende el Tribunal que «el marco competencial en materia de régimen local difiere de un modo esencial en el caso de Navarra, pues las previsiones de la LORAFNA, en la parte que reflejen derechos históricos, enraízan en la disposición adicional primera de la Constitución que, por lo que aquí interesa, desplaza respecto a esta entidad foral la competencia estatal de dictar legislación básica ex art. 149.1.18. ${ }^{a}$ CE (STC 140/1990, de 20 de noviembre, en cuanto a la legislación básica sobre funcionarios públicos, en especial, FFJJ 2, 3 y 4)».

A continuación, recuerda el Tribunal que la «organización concejil» se ha mantenido en Navarra de forma ininterrumpida, por lo que forma parte de los derechos históricos que ostenta «al amparo de lo establecido en la Ley Paccionada de dieciséis de agosto de mil ochocientos cuarenta y uno, en el Real Decretoley Paccionado de cuatro de noviembre de mil novecientos veinticinco y disposiciones complementarias», según el artículo 46.1 a) LORAFNA. También se refiere a ellos expresamente el artículo 46.2 LORAFNA, que alude «a los Municipios, Concejos y Entidades Locales de Navarra». Por todo ello concluye que esta materia se incardina en la competencia reservada por el artículo 46 LORAFNA al ente foral en materia de Administración local, que no queda en este punto constreñida por la legislación básica estatal.

Esta conclusión no lleva al Tribunal Constitucional a declarar la inconstitucionalidad del artículo 24 bis LBRL, que lógicamente es aplicable en otras Comunidades Autónomas. Precisa el Tribunal que la disposición adicional tercera de la LBRL, que expresamente prevé que «la presente Ley regirá en Navarra en lo que no se oponga al régimen que para su Administración local establece el art. 46 LORAFNA», es también aplicable a los preceptos introducidos en la misma por la LRSAL y concluye que el nuevo artículo 24 bis LBRL «no invade la competencia del ente foral dado que la disposición adicional tercera de la Ley de Bases de Régimen Local deja claro que el ámbito de aplicación de aquél no alcanza al territorio foral. Todo ello sin perjuicio de que a las entidades locales navarras le sean aplicables los controles de eficiencia que, en virtud del art. 149.1.14 CE, el Estado ha dispuesto en la Ley Orgánica 2/2012, de 27 de abril, de estabilidad presupuestaria y sostenibilidad financiera, con las especialidades que en su aplicación al territorio foral prevé la disposición adicional tercera de esta última norma» (STC 180/2016, FJ 5).

El Parlamento de Navarra también recurrió la disposición transitoria cuarta de la LRSAL, relativa a la supresión de entidades inframunicipales ya constituidas. El Tribunal Constitucional desestimó esa impugnación por las mismas razones; es decir, por entender que no era aplicables a la Comunidad Foral, aunque consideró que en este caso «la previsión que determina la no aplicabilidad de esta disposición [*] no es la disposición adicional tercera de la Ley de Bases de Régimen Local sino la disposición adicional segunda de la LRSAL, norma esta última que en su apartado primero presenta una regla general similar a la que está contenida en aquélla y hemos tenido en cuenta respecto del art. 24 bis LBRL» (STC 180/2016, FJ 5).

\section{El régimen especial del País Vasco}

Una solución similar es la prevista para la Comunidad Autonoma del País Vasco ${ }^{36}$, ya que la LRSAL también modificó la disposición adicional segunda de la LBRL, que reconoce la singularidad del régimen local en esta Comunidad Autónoma. Encuentra esta su fundamento en la disposición adicional primera de la Constitución y en los artículos 3, 24.2 y 37 del Estatuto de Autonomía para el País Vasco, que amparan las peculiaridades históricas de las Entidades Locales de los Territorios Históricos de Araba/Álava, Gipuzkoa y Bizkaia ${ }^{37}$. Además, la propia LRSAL contiene una disposición similar, la adicional primera, que declara su apli-

36 VELASCO CABALLERO (2014a) y GALÁN GALÁN (2015: 7) se han ocupado de las particularidades que presenta las cláusulas de excepción de la LRSAL aplicables a la Comunidad Autónoma del País Vasco.

37 También modifica la LRSAL el texto de la disposición adicional octava del Texto Refundido de la Ley reguladora de las Haciendas Locales, aprobado mediante Real Decreto Legislativo 2/2004, de 5 de marzo, adaptando el régimen económico-financiero especial del que disfrutan las entidades locales del País Vasco en los términos de la Ley del Concierto Económico a las técnicas de control 
cación a la Comunidad Autónoma del País Vasco «sin perjuicio de las particularidades que resultan de la Ley Orgánica 3/1979, de 18 de diciembre, por la que se aprueba el Estatuto de Autonomía para el País Vasco, de la disposición final tercera de la Ley Orgánica 2/2012, de 27 de abril, de Estabilidad Presupuestaria y Sostenibilidad Financiera, y de las demás normas que actualicen los derechos históricos de los territorios forales».

Son reglas similares a las comentadas en relación con el régimen especial navarro -más claras incluso-, por lo que se puede concluir que en materia de entidades inframunicipales en el País Vasco prevalece la normativa foral dictada en cada Territorio Histórico para adapta sus derechos históricos frente a lo dispuesto en la legislación estatal de régimen local, cuando entre en conflicto con tales derechos (RAZQUIN LIZARRAGA, 2014: 144-145). Esto supone que no serían de aplicación en el territorio de esta Comunidad Autónoma las limitaciones que introduce la LRSAL en materia de entidades de ámbito territorial inferior al municipio que resulten contrarias a la regulación foral, salvaguardando así las formas tradicionales de organización de los Territorios Históricos, como los concejos alaveses ${ }^{38}$.

Siguiendo esa lógica, el Parlamento Vasco ha aprobado la Ley 2/2016, de 7 de abril, de Instituciones Locales de Euskadi, en cuyo artículo 2 se otorga la consideración de entidades locales a «Los concejos y cualesquiera otras entidades locales territoriales de ámbito inferior al municipio, conforme a la normativa foral existente en cada territorio y lo dispuesto en la legislación básica de régimen local» (artículo $2.1 \mathrm{~b}$ ) de la Ley 2/2016). Y en el artículo 13 se atribuye a los órganos forales de los respectivos territorios históricos vascos las competencias normativas y ejecutivas, así como las de carácter económico-financiero, sobre las entidades locales menores.

\section{LAS ENTIDADES DE ÁMBITO TERRITORIAL INFERIOR AL MUNICIPIO TRAS LA LRSAL}

Una vez determinado el alcance de la reforma de 2013 sobre la regulación de las entidades de ámbito territorial inferior al municipio es necesario analizar el contenido de los preceptos de carácter básico que específicamente se refieren a las mismas.

Como resultado de la reforma se han configurado dos soluciones organizativas distintas, con estatutos muy diferentes: la tradicional de las entidades locales menores y otra nueva, como órganos municipales desconcentrados. A continuación se exponen las modificaciones que afectan a las entidades de ámbito territorial inferior al municipio. En el siguiente apartado se analiza la regulación básica sobre los nuevos órganos municipales desconcentrados, impropiamente llamados «entes de ámbito territorial inferior al municipio».

\section{La supresión del artículo 45 LBRL y la subsistencia de las entidades inframunicipales existentes}

La LRSAL dejó sin contenido el artículo 45 LBRL, derogando así la regulación básica sobre entidades de ámbito territorial inferior al municipio. También suprimió la mención contenida en el artículo 3.2.a) LBRL a las «Entidades de ámbito territorial inferior al municipal, instituidas o reconocidas por las Comunidades Autónomas, conforme al artículo 45 de esta Ley», lo que podía hacer pensar que de ese modo se negaba la consideración de entidad local a las entidades inframunicipales que previamente habían sido instituidas o reconocidas en los términos del artículo 45. Pero esa conclusión sería errónea, puesto que ni el vaciamiento del artículo 45 LBRL ha supuesto la desaparición de las entidades de ámbito territorial inferior al municipio, ni la supresión de la mención del artículo 3.2 conlleva que las existentes pierdan su condición de entidades locales.

Aunque en los primeros borradores del anteproyecto de LRSAL se proponía la disolución de todas las entidades de ámbito territorial inferior al municipio, la fuerte oposición que levantó esa medida ${ }^{39}$ provocó la incorporación a la LRSAL de la disposición transitoria cuarta, en la que se establece que mantienen su personalidad jurídica y la condición de entidad local todas las entidades de este tipo existentes en el momento de entrada

financiero que introduce la LRSAL, atribuyendo su competencia a los Territorios Históricos en lugar de a la Administración General del País Vasco.

${ }^{38}$ BAZAKO y ETXANOBE (2015) han destacado que éste era el objetivo perseguido con la negociación llevada a cabo por el grupo nacionalista vasco en el Congreso de los Diputados durante la tramitación de la LRSAL.

${ }_{39}$ Esa oposición política queda patente en las alegaciones de la Federación Española de Municipios y Provincias al anteproyecto de Ley, en las que se oponía rotundamente a la pérdida de la personalidad jurídica de estas entidades y de su carácter de entidades locales. Sí llegaron a admitir la disolución de las entidades de ámbito territorial al municipio que no presentasen sus cuentas, aunque se proponía la ampliación del plazo previsto en el anteproyecto. 
en vigor de la Ley ${ }^{40}$. Debe tenerse en cuenta además que la LRSAL ha modificado los artículos 45 y 3.2 LBRL, pero no ha eliminado la referencia del artículo 4.2 LBRL a dichas entidades, por lo que también pueden ejercer las potestades propias de las Administraciones Públicas de carácter territorial que las leyes autonómicas les hayan atribuido (o les atribuyan). Puede parecer un resultado discordante, debido sin duda a los importantes cambios sufridos por el proyecto de ley en cuestiones fundamentales, a las rectificaciones asumidas en contra de los objetivos iniciales ${ }^{41}$, pero sobre todo a la deficiente técnica empleada para incorporar todo ello a los textos legales que se modificaron, ya que no se prestó la debida atención a la coherencia del texto resultante ${ }^{42}$.

Por tanto, siguen existiendo las entidades de ámbito inferior al municipio existentes a la entrada en vigor de la LRSAL, que también conservan la condición de entidad local. Es un gran número de Administraciones, que incluso podía aumentar a medida que concluyeran los procedimientos de constitución de este tipo de entes iniciados antes del 1 de enero de 2013, como se explicará más adelante. Aunque solo gestionan el $6 \%$ del gasto del sector público local, suponen más del $25 \%$ de las entidades locales existentes ${ }^{43}$. Cabe por ello preguntarse si fue razonable vaciar el artículo 45 LBRL y dejar a todas estas entidades sin una regulación estatal básica. Desde luego fue una decisión deliberada ${ }^{44}$, pero no por ello deja de sorprender que, a pesar de la extensión de las bases en muchas de las materias reguladas en la LBRL, en este caso el legislador estatal renunciase a establecer una regulación común para las entidades de ámbito territorial inferior al municipio, derogando la que existía y entregando conscientemente la completa caracterización de este tipo de entes al legislador autonómico ${ }^{45}$. Parece al menos contradictorio con la funcionalidad de las bases que lo que durante años ha sido básico con el argumento de ser una regulación común, esencial y necesaria para este tipo de entidades, deje repentinamente de serlo, a pesar de que ni han desaparecido las entidades ni se ha producido una modificación de calado en su régimen jurídico.

\section{Las nuevas causas de disolución de entidades de ámbito territorial inferior al municipio}

Las entidades de ámbito territorial inferior al municipio conservarán su estatus mientras no incurran en alguna de las causas de disolución previstas en la legislación de régimen local o terminen finalmente segregándose del municipio matriz ${ }^{46}$. Sobre esta cuestión también ha incidido la LRSAL, que regula dos nuevas causas de disolución.

\section{a) Disolución por incumplimiento del deber de presentación de cuentas}

La primera se encuentra en el apartado segundo de la disposición transitoria cuarta de la LRSAL, en la que se establece que «con fecha de 31 de diciembre de 2014, las entidades de ámbito territorial inferior al

40 No debe olvidarse tampoco que otras normas estatales relevantes, significativamente la legislación sobre estabilidad presupuestaria, también consideraban entidades locales a las entidades de ámbito territorial inferior al municipio, aunque no las asimilan a los municipios a todos los efectos. Por ejemplo, no se les permitió acogerse al plan de pagos a proveedores, porque no participaban en los tributos del Estado (que sirven de garantía de los préstamos). Y ello a pesar de que muchas de las entidades inframunicipales se financian con cargo a esa participación municipal, porque así está previsto en los convenios que han suscrito con los municipios en los que se integran.

${ }^{41}$ La disposición por la que conservan la condición de entidad local aquellas que ya disfrutaban de ella se introdujo en una enmienda en el Senado el 18 de diciembre de 2013, solo nueve días antes de la promulgación de la LRSAL.

42 Un claro ejemplo de esa falta de atención es que, pese a haber dejado sin contenido ese precepto, en la redacción vigente de los artículos 22, 47, 50 y 123 LBRL aún se alude expresamente a las «entidades a que se refiere el artículo $45 »$.

43 En 2014 el número de entidades de ámbito territorial inferior al municipio (EATIM) era de 3.711, que representaba el 28\% del total de entes que integran el sector público local. Castilla y León era la Comunidad Autónoma que más entidades tenía (2215, un $60 \%$ del total), seguida de Cantabria (520, un 14\%). Ese número se ha mantenido con mínimas variaciones (en la actualidad son 3.708 ), puesto que algunas de esas entidades finalmente se han constituido en municipios por segregación, como más adelante se expondrá. Sobre la situación de las mismas, aunque con datos del año 2012, es muy expresiva la «foto» tomada por GALÁN y GALINDO (2015: 48-58) en su análisis del Registro de Entidades Locales y la tipología que realizan.

44 No puede pensarse en este caso que fue un descuido más, porque durante la tramitación parlamentaria se advirtió de ello y se propuso que se mantuviera el artículo 45 LBRL para que se aplicase a las entidades existentes y a las que se encontraban en proceso de constitución, aunque la enmienda no fue admitida. Y desde luego no cabe entender que a estas entidades les resulte aplicable el nuevo artículo 24 bis LBRL, porque este tiene por objeto entes sin personalidad jurídica. GALÁN y GALINDO (2015: 81) han señalado que en esta cuestión la LRSAL profundiza en la interiorización autonómica del régimen jurídico de este tipo de entidades, a pesar de que uno de los reproches más generalizados a la misma es precisamente el de vulnerar las competencias autonómicas.

45 Siguen vigentes los artículos 38 a 45 del Real Decreto Legislativo 781/1986, de 18 de abril, por el que se aprueba el texto refundido de las disposiciones legales vigentes en materia de Régimen Local, puesto que la LRSAL no contiene referencia alguna a la legislación estatal supletoria sobre este tipo de entidades.

46 Sobre las causas y efectos de la disolución vid. PIZARRO NEVADO (2002: 125-131). 
Municipio deberán presentar sus cuentas ante los organismos correspondientes del Estado y de la Comunidad Autónoma respectiva para no incurrir en causa de disolución». En el apartado tercero se añade que la no presentación de cuentas «ante los organismos correspondientes del Estado y de la Comunidad Autónoma respectiva» es causa de disolución ${ }^{47}$.

Resulta desconcertante lo genérico de la circunstancia que llevaría a la disolución y el automatismo con el que aparentemente operaría, pues esta causa de disolución se fundamentaba en el incumplimiento de una genérica obligación formal, la de presentación de cuentas en una fecha determinada, pero sin que se definieran a qué ejercicios se extendía la obligación, ni contemplar qué sucedía en caso de cumplimiento extemporáneo por razones justificadas, por ejemplo, o cuando las cuentas se hubieran remitido en plazo pero antes de que fueran aprobadas por el Pleno ${ }^{48}$. Sin embargo, el Tribunal Constitucional ha considerado razonable esa indefinición porque así no solo se deja en manos de las Comunidades Autónomas la adopción de la medida, sino que conservan cierto margen «para determinar el alcance de la obligación de presentación de cuentas, apreciar el incumplimiento que acarrea aquellas consecuencias y, afirmado el incumplimiento, decidir entre disolver sin más la entidad local menor o conservarla como "forma de organización desconcentrada"» [STC 41/2016, FJ 7.c)].

Era lógico pensar que la disolución no se produciría automáticamente, sino que sería necesario constatar el incumplimiento previamente. La misma disposición transitoria precisa que la disolución «será acordada por Decreto del órgano de gobierno de la Comunidad Autónoma respectiva», aunque ese inciso ha sido declarado inconstitucional ${ }^{49}$, por lo que corresponde al legislador autonómico determinar el órgano, el procedimiento y la forma que ha de adoptar esta decisión, garantizando la intervención de todas las entidades afectadas, entre las que se encuentran los municipios. Y no solo eso, puesto que -como se reconoce en la STC 41/2016 [FJ 7.c)]- esa legislación también debe «determinar el alcance de la obligación de presentación de cuentas», y establecer los criterios para apreciar el incumplimiento y para decidir entre disolver simplemente la entidad o transformarla en una forma de organización desconcentrada ${ }^{50}$.

Pero la mayor crítica que merece la disposición es la desproporción de la medida asociada al incumplimiento ${ }^{51}$. Es evidente que la disposición transitoria cuarta responde a un problema real, como era que muchas entidades no presentaban sus cuentas. Pero no parece proporcionado que se imponga la disolución de la entidad inframunicipal cuando la consecuencia no es la misma en el supuesto de que sean los municipios los que incumplan el mismo deber ${ }^{52}$, ni es la prevista en otras leyes cuando son otras Administraciones las que incumplen obligaciones del mismo tipo ${ }^{53}$. Esa desproporción resulta aún más evidente si se considera que la gravosa medida se introdujo precisamente cuando la tendencia de los últimos años era la de la re-

47 Aunque la constitucionalidad de esta disposición fue cuestionada por la Asamblea de Extremadura, el TC ha rechazado el recurso en este punto razonando que, a pesar de que «la organización interna municipal corresponde a los propios Ayuntamientos en el marco de la legislación sobre régimen local, que en este punto ha de ser, en principio, prevalentemente autonómica», existen intereses supraautonómicos que pueden justificar una regulación básica que imponga la supresión preceptiva de estructuras organizativas o su conversión preceptiva en formas de organización desconcentrada. Reconoce que «la medida incide directamente en la autonomía municipal (arts. 137 y $140 \mathrm{CE}$ ) con el fin de proteger intereses supraautonómicos, en general, ahorrar dinero público y facilitar el cumplimiento de los mandatos constitucionales de eficiencia, eficacia y estabilidad presupuestaria (arts. 31.2, 103.1 y 135 CE), en particular» [STC 41/2016, FJ 7 c)].

48 Sobre las continuadas denuncias de la indefinición de esta disposición durante su tramitación parlamentaria vid. GALÁN y GALINDO (2015: 69-71).

49 El Tribunal Constitucional ha declarado en su sentencia 41/2016 que el órgano autonómico que «ha de adoptar el acuerdo de disolución en este caso y cómo ha de hacerlo son esencialmente "cuestiones de organización administrativa" (STC 194/2012, de 31 de octubre, FJ 7) que pertenecen a la potestad de autoorganización de la Comunidad Autónoma. En este supuesto, no hay razones constitucionales que justifiquen que las bases desciendan a la regulación de estos detalles. Por eso la determinación del legislador estatal infringe los arts. 148.1.1 CE y 9.1.1 del Estatuto de Autonomía de Extremadura».

50 VELASCO CABALLERO (2014b: 52) va más allá incluso y ha sugerido que la Comunidad Autónoma puede decidir sobre la continuidad de la entidad inframunicipal en función de sus propios criterios de política territorial y local.

${ }^{51}$ Así lo denunciaba el Consell de Garanties Estatutàries, apuntando que el incumplimiento de este trámite no indica por sí mismo que se haya producido una vulneración de las exigencias derivadas de la legislación sobre estabilidad presupuestaria y sostenibilidad financiera, por lo que consideraba la disolución una consecuencia demasiado drástica (Dictamen 8/2014, de 27 de febrero, sobre la Ley 27/2013, de 27 de diciembre, de racionalización y sostenibilidad de la Administración local). En términos similares se pronunciaron ALMEIDA CERREDA, Marcos (2014: 24-25) y GALÁN y GALINDO (2015: 73).

52 Los datos recogidos en los informes del Tribunal de Cuentas muestran que las entidades de ámbito territorial inferior al municipio no tenían un grado de cumplimiento mucho peor que el de los pequeños municipios. En el Informe de Fiscalización del Sector Público Local, ejercicio 2014, elaborado por el Tribunal de Cuentas a partir de la información de las cuentas generales del citado ejercicio económico rendidas por las entidades locales (fecha de aprobación: 30 de junio de 2016) se comprueba que el 31 de diciembre de 2015 habían rendido cuentas de 2014 solo el $76 \%$ de los municipios y el $74 \%$ de las entidades inframunicipales.

53 Una medida más proporcionada e igualmente eficaz, y así lo ha propuesto también el Tribunal de Cuentas, podría ser impedir que las Administraciones incumplidoras puedan acudir a las convocatorias de ayudas y subvenciones. 
ducción del grado de incumplimiento de la obligación de rendición de cuentas, por lo que después de años de tolerancia era difícil imaginar que los Gobiernos autonómicos acordasen una disolución por esta causa ${ }^{54}$.

Debe precisarse que esa desproporción no se ha considerado razón suficiente para declarar inconstitucional la disposición transitoria por vulnerar el principio de interdicción de la arbitrariedad consagrado en el artículo 9.3 CE, como planteó el Gobierno de Cataluña en el recurso de inconstitucionalidad núm. 20062014. EI TC rechazó ese motivo de impugnación en la STC 93/2017 por dos razones. En primer lugar, por el comentado margen de configuración que se deja a las Comunidades Autónomas para definir el alcance de la obligación de presentación de cuentas y los efectos de su incumplimiento, lo que en palabras del TC «viene en cierto modo a facilitar que las Comunidades Autónomas puedan asegurar que los efectos jurídicos que se produzcan (disolución o conversión en forma de organización desconcentrada) sean proporcionales a la gravedad del incumplimiento efectivamente producido». Y en segundo lugar porque negó que para determinar si la regulación de la disposición transitoria cuarta vulnera el principio de interdicción de la arbitrariedad deba utilizarse como parámetro de control el canon de proporcionalidad, que entiende que es propio «de las normas constitucionales de protección de derechos fundamentales sustantivos, así como del derecho fundamental a acceder a la jurisdicción previsto en el artículo 24.1 CE [por todas, SSTC 136/1999, de 20 de julio, FJ 22; 60/2010, de 7 de octubre, FJ 7 b), y 209/2013, de 16 de diciembre, FJ 3]». Por tanto, en la STC 93/2017 el Tribunal no hizo un juicio de adecuación, necesidad y proporcionalidad en sentido estricto, sino que recordó la doctrina expuesta en las SSTC 118/2016, 96/2002 y 215/2014 para insistir en que el control de la interdicción de la arbitrariedad debe hacerse con mucha prudencia «para evitar constricciones indebidas al poder legislativo respetando sus diferentes opciones políticas» y que en ese control únicamente puede verificar si la decisión adoptada «carece de toda explicación racional» o «establece una discriminación», "sin que sea pertinente realizar un análisis a fondo de todas las motivaciones posibles de la norma y de todas sus eventuales consecuencias». Siguiendo ese planteamiento, el Tribunal razonó que «las consecuencias asociadas al incumplimiento de la obligación de presentación de cuentas serían contrarias al artículo 9.3 CE solo si pudiéramos afirmar que carecen de toda explicación racional después de realizar un escrutinio deferente con los amplios márgenes de configuración del legislador», lo que no apreció en este concreto supuesto por considerar que la disposición transitoria cuarta de la LRSAL persigue un objetivo legítimo: «incentivar a las entidades locales menores a ordenar, equilibrar y dar a conocer sus cuentas». El Tribunal no entra por tanto a considerar la proporcionalidad de las consecuencias asociadas al incumplimiento de la obligación de presentación de cuentas porque considera que no están completamente definidas y que, además, esta no es el parámetro constitucional para controlar una eventual vulneración del principio de interdicción de la arbitrariedad, pero de su razonamiento sí puede deducirse el deber del legislador autonómico de atemperar los efectos del incumplimiento en consideración a las circunstancias concurrentes en cada caso.

Habría que añadir que las consecuencias de la disolución no solo son indeseables para la entidad de ámbito territorial inferior al municipio. También los municipios rechazarán en muchos casos esta solución, porque tendrán que asumir nuevas responsabilidades (Ios servicios que prestaba la entidad disuelta) y cargas que pueden ser muy pesadas, como la incorporación del personal de la entidad extinguida y la subrogación en sus derechos y sobre todo en sus obligaciones (apartado tercero de la disposición transitoria cuarta). Todo ello sin contar además con el malestar social que sin duda generaría la medida.

Todo lo anterior podría explicar la falta de desarrollo autonómico de la disposición transitoria cuarta de la LRSAL y, por tanto, la completa desactivación de su eficacia.

54 De la ineficacia de esta medida es reflejo la situación descrita en el citado Informe de Fiscalización del Sector Público Local, ejercicio 2014, en el que se denuncia la interrupción de la tendencia al alza en la rendición de cuentas que venía produciéndose en los últimos ejercicios, tanto en los municipios como en las entidades inframunicipales. El 31 de diciembre de 2015 solo habían rendido cuentas de 2014 el $76 \%$ de los municipios, mientras que ese porcentaje había sido del $82 \%$ en el ejercicio anterior. Pero quizá el dato más llamativo sea el importante descenso de la rendición de cuentas de las entidades de ámbito territorial inferior al municipio después del máximo alcanzado el 31 de diciembre de 2014, ante la amenaza de disolución. En esa fecha rindieron la cuenta general del ejercicio 2013 solo 2068 entidades inframunicipales, mientras que el resto (1103 entidades) rindieron la cuenta general del ejercicio 2013 con posterioridad o no la han rendido todavía y no por ello han sido disueltas. De acuerdo con los datos disponibles en el portal Rendición de Cuentas en junio de 2017 (http://www.rendiciondecuentas.es/es/observatorioderendicion/rendiciontipoentidad.html), se ha pasado de una rendición de cuentas del ejercicio 2013 de un 97,32 \% (si se incluye la rendición extemporánea) a un 90,95 \% en relación con el ejercicio 2014. Si se considera el ejercicio 2015 , se comprueba que solo rindieron sus cuentas en plazo el $49,45 \%$ de las entidades inframunicipales, porcentaje que sube hasta el $84,19 \%$ si se considera la rendición extemporánea hasta junio de 2017. 


\section{b) Disolución por exigencia de un plan económico-financiero}

Una segunda causa de disolución se contiene en el nuevo artículo 116 bis LBRL, que regula el contenido de los planes económico-financieros que deben formular los municipios que incumplen los objetivos de estabilidad presupuestaria, deuda pública o la regla de gasto. Si se da alguna de esas circunstancias, el municipio está obligado a formular uno de esos planes con el contenido establecido en el apartado segundo. Pues bien, una de las medidas previstas con carácter obligatorio es la «supresión de entidades de ámbito territorial inferior al municipio que, en el ejercicio presupuestario inmediato anterior, incumplan con el objetivo de estabilidad presupuestaria o con el objetivo de deuda pública o que el período medio de pago a proveedores supere en más de treinta días el plazo máximo previsto en la normativa de morosidad».

Esta es la redacción dada en el Senado, que de nuevo actuó mitigando el injustificable trato que se quería aplicar a las entidades de ámbito territorial inferior al municipio. En su redacción original el proyecto de ley contemplaba la supresión de las entidades inframunicipales sin más precisiones, aunque fueran sostenibles financieramente, si no lo era el municipio y este se veía obligado a aprobar un plan económico-financiero. Soportaban así las entidades de ámbito territorial inferior al municipio las consecuencias de una situación que no les era imputable y que dejaba además su supervivencia en manos del municipio de adscripción.

Pero la redacción definitiva también resulta problemática, porque no se precisan debidamente cuestiones tan relevantes como el tipo de entidades que activarían el precepto cuando formulan un plan económicofinanciero o el régimen aplicable al proceso de disolución, lo que obliga a una compleja tarea de interpretación ${ }^{55}$. Además, la disolución prevista puede considerarse hasta cierto punto desproporcionada (ALMEIDA CERREDA, 2014: 24-25), ya que el artículo 116 bis LBRL contempla medidas mucho más contundentes que las previstas en la Ley Orgánica 2/2012 para dar respuesta a una situación de carácter coyuntural. Porque en el fondo la situación económico-financiera que el plan pretende resolver tendrá en muchas ocasiones un carácter temporal y, sin embargo, la LRSAL impone forzosamente medidas permanentes e irreversibles, entre ellas la supresión de la entidad de ámbito territorial inferior al municipio. Habría sido más adecuado, al menos en una primera fase, intentar sanear la entidad inframunicipal, como se pretende hacer con el municipio a través del plan. Esto último es particularmente necesario si consideramos que no existe una regulación que afronte decididamente la financiación de las entidades inframunicipales, que en este extremo quedan a merced del municipio y de las restantes administraciones territoriales y, por tanto, su supervivencia está supeditada a condiciones que no siempre controlan. Aunque algunas mantienen unas fluidas relaciones de colaboración con el municipio en que se enclavan, en otros casos no es así, sino todo lo contrario, por lo que en el supuesto de que el municipio matriz afrontase dificultades financieras la entidad inframunicipal se vería casi inexorablemente abocada a la disolución, consecuencia esta que además el municipio podría eludir aunque su situación financiera fuera equiparable.

\section{Régimen aplicable a las entidades en proceso de constitución}

La disposición transitoria quinta de la LRSAL regula los procedimientos de constitución de entidades de ámbito territorial al municipio en tramitación al momento de su entrada en vigor. No debe sorprender que se atienda a una situación siempre problemática, aclarando cuál debe ser el régimen aplicable a la entidad surgida del proceso y, por tanto, cuál sea su naturaleza jurídica. En lo que sí se aparta la disposición transitoria quinta de la práctica habitual es en la forma de determinar ese régimen, porque lo usual es que en estos casos se aplique la legislación vigente el día de inicio del procedimiento, aunque se resuelva con posterioridad a la entrada en vigor de una nueva regulación, o alternativamente aplicar la legislación vigente el día que se resuelve el procedimiento, sin entrar a considerar la fecha de inicio del procedimiento. En este supuesto no se opta ni por una ni por otra regla, sino por una combinación de ambas.

En la disposición transitoria quinta se prevé que los procedimientos para la constitución de entidades de ámbito territorial inferior al municipio en tramitación el día de entrada en vigor de la LRSAL, que fue el 31 de diciembre de 2013, se resolverían de dos formas en función de cuál hubiera sido el día de iniciación del procedimiento. Si el procedimiento se había iniciado «antes del 1 de enero de 2013 [ $\cdots$ ], una vez que se constituya, lo hará con personalidad jurídica propia y con la condición de Entidad Local y se regirá por lo dispuesto en la legislación autonómica correspondiente». Esto suponía que, si la resolución era favorable

\footnotetext{
${ }^{55}$ Al respecto de esta cuestión vid. GALÁN GALÁN y GALINDO CALDÉS (2015: 77-81).
} 
a la constitución de la entidad, esta tendría personalidad jurídica propia y la naturaleza de entidad local, en las mismas condiciones que las que se hubieran constituido antes de la entrada en vigor de la LRSAL ${ }^{56}$. Esa identidad de régimen jurídico no puede reducirse exclusivamente al previsto en la legislación autonómica, a pesar de lo que diga la disposición transitoria; también les será de aplicación la legislación estatal sobre este tipo de entidades locales, tanto la dictada con carácter básico, como la que lo tiene supletorio. En particular les será de aplicación las obligaciones y las causas de disolución comentadas en el apartado anterior.

Lo anterior no regía si el procedimiento de constitución de la entidad inframunicipal se había iniciado después del 1 de enero de 2013, porque en tal caso una interpretación a contrario sensu de la disposición transitoria quinta llevaba a concluir que tras la entrada en vigor de la LRSAL no podría constituirse una entidad con personalidad jurídica propia, sino que el núcleo de población a lo sumo podría alcanzar la condición de órgano desconcentrado; es decir, la de los nuevos entes de ámbito territorial inferior al municipio regulados en el artículo 24 bis LBRL. Obviamente el propósito de esta regla era evitar que ante la inminencia del cambio legal se produjese una explosión de iniciativas para la constitución de entidades inframunicipales o mitigar en parte sus efectos. Pero la solución ideada en realidad genera nuevos problemas, porque el resultado al que se llega ni era el deseado por el promotor de la iniciativa ni por el municipio (cuando la iniciativa partiera de la población del núcleo separado) al que, desconociendo su potestad de organización, se iba a imponer un órgano de gestión desconcentrada. Como es lógico la esperanza de vida de ese nuevo órgano puede ser muy corta, si es que el proceso no se ve truncado por el desistimiento de sus promotores. Hubiera sido más adecuado, y más respetuoso con la competencia autonómica sobre régimen local, que la disposición transitoria incorporase al procedimiento de constitución una fase de composición de intereses de las Administraciones implicadas y una mayor libertad de apreciación para las Comunidades Autónomas en la decisión final.

\section{EL RÉGIMEN BÁSICO DE LOS NUEVOS ÓRGANOS DESCONCENTRADOS}

Aún debe analizarse la regulación contenida en el nuevo artículo 24 bis LBRL, que incorpora a dicha ley otra modalidad de organización territorial desconcentrada bajo la denominación de «entes de ámbito territorial inferior al municipio». A pesar de lo que pudiera sugerir su nombre, son simples órganos administrativos, que carecen de personalidad jurídica propia y, por supuesto, del carácter de entidad local.

Como sucede con otras circunscripciones territoriales desconcentradas, la regulación de esta forma organizativa también se entrega casi por completo a las Comunidades Autónomas, que pueden decidir si desarrollan la figura en su territorio y qué configuración darle en cada caso, sin que del artículo 24 bis se deriven grandes condicionantes ${ }^{57}$. Al contrario, esa baja densidad normativa deja sin justificación el propio precepto y un reguero de dudas importantes.

\section{Denominación y naturaleza jurídica}

Es urgente que la legislación autonómica les asigne una denominación adecuada, ya que el término «ente» sugiere una existencia autónoma del municipio de la que no disfrutan los órganos desconcentrados. Debe evitarse que, cuando se constituyan estos órganos, puedan confundirse con las verdaderas «entidades de ámbito territorial inferior al Municipio» con las que van a coexistir, porque los llamados entes de ámbito territorial inferior al Municipio carecen de personalidad jurídica y, consecuentemente, no pueden ser entidades locales.

En ello se insiste innecesariamente en el apartado primero el artículo 24 bis LBRL, cuando los define como una forma de organización desconcentrada del municipio. Con seguridad este fue el motivo de la supresión del inciso del artículo 3.2 LBRL que aludía a las entidades de ámbito territorial inferior al municipio, puesto que en los primeros borradores de la LRSAL se proponía la supresión de cualquier forma de entidad inframunicipal descentralizada y se utilizaba esa expresión para nombrar a los que ahora se llama entes de ámbito territorial inferior al municipio. Sin embargo, el propósito inicial cambió durante la tramitación de la LRSAL y finalmente se mantuvieron las entidades inframunicipales existentes, conservando todas ellas la condición de

56 En aplicación de esta regla en 2014 se crearon las entidades municipales descentralizadas de Sant Miquel de Balenyà, en el municipio de Seva (Barcelona), y de L'Estartit, en el municipio de Torroella de Montgrí (Girona), la entidad local autónoma de Bobadilla Estación, en el término municipal de Antequera (Málaga) y la entidad local menor de Itziar, en el término municipal de Deba (Gipuzkoa).

57 En la STC 41/2016 se afirma que «[e]l art. 24 bis LBRL sigue sin incluir reglas precisas sobre creación, organización y competencias (art. 24 bis LBRL). Los propios municipios y, en su caso, las Comunidades Autónomas habrán de establecerlas». 
entidades locales. Nada ha cambiado en su régimen jurídico que justifique, por tanto, la modificación del artículo 3.2 LBRL. Ni puede explicarse por la eventual confusión que pudiera suscitar la similitud terminológica de los entes de ámbito territorial inferior al municipio, porque el artículo 24 bis se encarga de subrayar que estos carecen de personalidad jurídica y consecuentemente no pueden disfrutar de tal condición.

Tampoco es fácil entender qué añade el artículo 24 bis LBRL a lo previsto en el artículo 24 de la misma $L^{L}{ }^{58}$, al margen de dejar meridianamente claro que los nuevos entes «carecerán de personalidad jurídica», que parece ser lo único que justifica su inclusión autónoma. No lo es desde luego su definición como forma de organización municipal desconcentrada para la administración de núcleos de población separados, porque esto ya tenía acomodo en el artículo 24 LBRL ${ }^{59}$. Tampoco lo será la referencia a la eficiencia del apartado tercero, que no hace sino acentuar una exigencia común a la creación de cualquier órgano municipal complementario, como es que responda a los principios de eficacia y economía organizativa ${ }^{60}$.

ALMEIDA CERREDA (2014: 23) sugiere que la razón de esta elección «podría ser que, con la misma, el legislador estatal pretende dar vida y promover la difusión de un nuevo subtipo de organismo inframunicipal, situado a medio camino entre los tradicionales órganos de gestión territorial desconcentrada y las antiguas entidades locales menores». Pero si ese era el propósito del legislador básico, debe adelantarse que ha hecho poco por alcanzar ese objetivo, puesto que para ello sería imprescindible dotar a estos nuevos órganos de más atribuciones y mayor autonomía de la que gozan los órganos regulados en el artículo 24 LBRL, lo que no se desprende necesariamente de la redacción del artículo 24 bis. Por el contrario, ni siquiera contiene ese precepto una mínima referencia al fin que persigue toda forma de gestión territorial desconcentrada, que es «facilitar la participación ciudadana en la gestión de los asuntos locales y mejorar ésta», lo que refleja una vez más es sesgo exclusivamente economicista de la reforma ${ }^{61}$.

\section{Procedimiento de creación, modificación y supresión}

Los llamados entes de ámbito territorial inferior al municipio no son órganos necesarios, forman parte de los órganos complementarios y, por tanto, corresponde a cada municipio decidir sobre su creación y configuración en el ejercicio de su potestad de autoorganización. No se afirma así expresamente en el artículo 24 bis LBRL, pero no puede ser de otra forma dada su naturaleza jurídica, al menos mientras la legislación autonómica no establezca un procedimiento de creación diferente ${ }^{62}$ (VELASCO CABALLERO, 2014: 52-53). Esta es además la previsión contenida en el artículo 24 LBRL, que debe entenderse aplicable también a la nueva modalidad de órganos desconcentrados.

58 Vid. TRAYTER JIMÉNEZ (2007: 671) o GALINDO CALDÉS (2014: 48).

59 En desarrollo de la previsión del artículo 24 LBRL el Real Decreto 2568/1986, de 28 de noviembre, por el que se aprueba el Reglamento de Organización, Funcionamiento y Régimen Jurídico de las Entidades Locales (ROF) y la legislación autonómica habían regulado distintos órganos territoriales de gestión desconcentrada: Juntas Municipales de Distrito (artículos 128 y 129 ROF), Juntas de Vecinos en la Ley 6/1988, de 25 de agosto, de Régimen Local de la Región de Murcia, etc. El artículo 65 TRLMRLC, permite que «los grupos de población que dentro de un municipio constituyen núcleos separados pueden constituirse como órganos territoriales de participación. La constitución es obligatoria cuando la mayoría de los vecinos interesados lo pida». Y la Ley 5/2010, de 11 de junio, de Autonomía Local de Andalucía (LAULA), contempla en sus artículos 109 y 111 la creación de circunscripciones territoriales desconcentradas que «podrán ser denominadas distritos, barrios, aldeas, pedanías u otras denominaciones de análoga significación».

${ }_{60}$ Como se exige con carácter general para todo tipo de entes y órganos en la legislación de régimen local. Así se dispone, por ejemplo, en el artículo 49 TRLMRLC o en el artículo 110 LAULA, donde se afirma que la «organización territorial del término municipal estará presidida por el principio de racionalidad y economía administrativa».

61 QUINTANA LÓPEZ, Tomás (1991: 151) explica como desde su origen la organización municipal desconcentrada ha estado conectada con la participación ciudadana. Sin embargo, en el apartado primero del artículo 24 bis se omite cualquier referencia a este objetivo y únicamente se indica que los entes de ámbito territorial inferior al municipio se crearán «para la administración de núcleos de población separados, bajo su denominación tradicional de caseríos, parroquias, aldeas, barrios, anteiglesias, concejos, pedanías, lugares anejos y otros análogos, o aquella que establezcan las leyes».

${ }^{62}$ Esa parece ser también la idea que asume la STC 19/2017, en la que el Tribunal Constitucional reconoce la competencia autonómica para regular dicho procedimiento (FJ 6). Pero es difícil compartir integramente la solución dada al concreto conflicto planteado, puesto que para salvar la regulación impugnada la sentencia impone una interpretación conforme con la legislación básica estatal que no parece que fuera la voluntad del Parlamento de Cataluña. Parece dudoso que al reformar el procedimiento de constitución de entidades descentralizadas regulado en el artículo 79 TRLMRLC se hiciera asumiendo que serviría exclusivamente para la constitución de los nuevos órganos desconcentrados, cuando el texto refundido no se modificó para incluir esa figura. Además, ignora el Tribunal las dificultades que esa interpretación suscitará al confrontarla con lo dispuesto en el artículo 24 bis, aunque era consciente de ello, como se desprende el inciso final del FJ 7, en el que se justifica no entrar a valorar la "posible incompatibilidad de esa configuración procedimental novedosa con el tenor del art. 24 bis LBRL» porque no había sido planteada por el Abogado del Estado en el recurso de inconstitucionalidad. 
Por eso resulta incomprensible la referencia del apartado segundo del artículo 24 bis a que el Ayuntamiento correspondiente «debe ser oído en todo caso», ya que es justamente el municipio el que acordará su creación. Arrastra aquí el artículo 24 bis LBRL una adherencia del artículo 45 que se ha dejado sin contenido, donde esta previsión tenía sentido porque la creación de entes con personalidad jurídica podía corresponder a la Comunidad Autónoma y era imprescindible la audiencia al municipio afectado en el procedimiento de constitución. $Y$ debe destacarse que no todas las leyes autonómicas habían mantenido esa regla, porque algunas atribuían a los municipios la decisión sobre la creación de entidades inframunicipales ${ }^{63}$. Lo que parece fuera de discusión es que el Estado, en el ejercicio de su competencia para establecer las bases de régimen jurídico de las Administraciones Públicas, pudiera establecer que la creación de estos órganos desconcentrados debe ser una decisión de la Comunidad Autónoma y no municipal.

Por tanto, puesto que estamos ante una cuestión de organización municipal (artículo 20.3 LBRL), en ausencia de una regulación específica, la creación de este tipo de «entes» puede realizarse en el reglamento de organización municipal, que regulará la existencia de estos órganos, su composición, atribuciones y funcionamiento. Pero también cabe que, como sucede frecuentemente en la creación de distritos ${ }^{64}$, los municipios dicten reglamentos específicos para la creación y regulación de entes de ámbito territorial inferior al municipio o incluso que se incluyan en la norma que regule los mecanismos de participación ciudadana.

Sí es relevante que el apartado segundo del artículo 24 bis LBRL contemple la iniciativa vecinal para impulsar el procedimiento de creación de los nuevos órganos. Quizá se pretenda con esta previsión que el ente de ámbito territorial inferior al municipio sirva para canalizar las demandas de participación en el gobierno de los asuntos de interés de las poblaciones separadas, pero es ingenuo pensar que sea así con órganos de tan poco recorrido. Es difícil imaginar que puedan cumplir esa función si las leyes autonómicas primero y los municipios después no les reconocen amplias atribuciones, financiación suficiente y una composición interna que no convierta a los nuevos órganos en meros ejecutores de las políticas del gobierno municipal, sino que incorpore una representación de los vecinos del núcleo separado y garantice que los nuevos «entes» sean verdaderos órganos de participación y gestión de los intereses vecinales.

Por último, el apartado tercero del artículo 24 bis LBRL supedita la decisión de crear un ente de ámbito territorial inferior al Municipio a que resulte una «una opción más eficiente para la administración desconcentrada de núcleos de población separados de acuerdo con los principios previstos en la Ley Orgánica 2/2012, de 27 de abril, de Estabilidad Presupuestaria y Sostenibilidad Financiera» (apartado tercero del artículo 24 bis LBRL). El Consejo de Estado denunció en su dictamen 567/2013 la generalidad de esta regla, porque «el anteproyecto no determina el modo en que haya de verificarse la condición, pues únicamente invoca la Ley Orgánica 2/2012, de 27 de abril, de estabilidad presupuestaria y sostenibilidad financiera, en la que no se incluye ningún requisito a estos efectos. Debería, pues, aclararse en el anteproyecto a quién corresponde tal constatación y establecerse las pautas que deban seguirse». La redacción final dada a la Ley no resuelve el problema, porque solo ha sustituido la remisión que se hacía en el anteproyecto a dicha Ley Orgánica en su totalidad por una genérica referencia a «los principios previstos en la Ley Orgánica 2/2012, de 27 de abril». Obviamente esto no corrige la insuficiencia denunciada, ya que ni arroja más luz sobre los criterios para verificar el cumplimiento del requisito, ni precisa quién debe hacer la comprobación. En relación con el primer aspecto, el apartado tercero es una disposición que no añade gran cosa al régimen municipal; es un mero recordatorio del régimen vigente en ese momento, puesto que los principios de la Ley Orgánica 2/2012, de Estabilidad Presupuestaria y Sostenibilidad Financiera más directamente conectados con la cuestión que nos ocupa son precisamente esos, los principios de estabilidad presupuestaria (artículo 3) y sostenibilidad financiera (artículo 4), así como el principio de eficiencia en la asignación y utilización de los recursos públicos ${ }^{65}$ (artículo 7), que ya eran exigibles en cada actuación municipal, porque las Corporaciones Locales estaban incluidas en su ámbito de aplicación. En relación con el segundo, a falta de legislación que desa-

${ }^{63}$ Así está previsto, por ejemplo, en el artículo 116 LAULA que para aprobar la creación de una entidad descentralizada exige el voto de la mayoría absoluta del número legal de miembros del pleno del ayuntamiento. La intervención posterior de la Consejería de la Junta de Andalucía competente sobre régimen local se reduce a recibir la comunicación del instrumento municipal de creación para su publicación en el Boletín Oficial de la Junta de Andalucía y, una vez constituidos sus órganos de gobierno, para proceder a su inscripción en el Registro Andaluz de Entidades Locales.

${ }^{64}$ Sobre el tratamiento dado a los distritos en este aspecto vid. GALINDO CALDÉS (2014: 93).

65 En el apartado tercero del artículo 7 se establece que «las disposiciones legales y reglamentarias, en su fase de elaboración y aprobación, los actos administrativos, los contratos y los convenios de colaboración, así como cualquier otra actuación de los sujetos incluidos en el ámbito de aplicación de esta Ley que afecten a los gastos o ingresos públicos presentes o futuros, deberán valorar sus repercusiones y efectos, y supeditarse de forma estricta al cumplimiento de las exigencias de los principios de estabilidad presupuesta- 
rrolle tan parca previsión, será el propio Ayuntamiento quién deba hacerlo, pues será este quien impulse y resuelva el procedimiento. Pero sobre todo el mayor reproche que merece este inciso es que olvida una vez más otros intereses dignos de consideración y con base constitucional expresa, como son los de acercar la acción administrativa a la población afectada y los de participación ciudadana ${ }^{66}$.

Nada se establece en la LRBRL sobre la modificación o supresión de este tipo de órganos, pero es lógico pensar que al no ser órganos necesarios los municipios pueden crearlos, modificarlos o suprimirlos discrecionalmente.

\section{Competencias, organización y funcionamiento}

Como todo órgano desconcentrado los entes de ámbito territorial inferior al municipio actúan en una parte del municipio, exclusivamente con funciones de gestión y limitadas a los asuntos que les asigne su instrumento de creación, a menos que la legislación autonómica eventualmente les reserve un elenco de atribuciones acorde con los intereses vecinales a los que se daría respuesta con esta figura. Y, por supuesto, aunque tampoco se especifique en el artículo 24 bis LBRL su acción deberá desarrollarse «sin perjuicio de la unidad de gobierno y gestión del municipio», para lo cual dispone este de las potestades de dirección características de las relaciones interorgánicas ${ }^{67}$.

Realmente es poco lo que la legislación básica puede establecer en esta materia que la jurisprudencia constitucional entrega ampliamente al legislador autonómico, admitiendo, por tanto, tantas soluciones como exija la variada realidad del territorio español. En dos de sus recientes sentencias recuerda el Tribunal Constitucional que «la sola previsión de que estos entes carecen de personalidad jurídica no elimina amplios espacios de desarrollo autonómico y autoorganización local. La personalidad jurídica propia o régimen de descentralización administrativa no implica un estatuto sustancialmente distinto, que garantice amplias esferas de autonomía a las entidades locales menores [ $\cdots$ ] Ciertamente, la ausencia de personalidad jurídica propia remite al sistema de imputación y control de actos característico de las relaciones interorgánicas. No obstante, las concretas tareas que correspondan a estas 'formas de organización desconcentrada' así como las facultades de control y supervisión que el municipio desarrolle respecto de ellas siguen dependiendo esencialmente de las opciones organizativas que adopten los propios entes locales en el marco de la legislación autonómica sobre régimen local y de las bases ex art. 149.1.18 CE» [STC 41/2016, FJ 7 b), y 168/2016, FJ 3 b)].

Como era por tanto previsible, el legislador básico, aunque tuviera en mente dar respuesta a la situación y a las demandas de los pequeños núcleos de población distintos de la capitalidad del municipio, al regular un nuevo órgano desconcentrado no iba a incluir referencia alguna a los órganos de gestión o de control, ni por supuesto al carácter electivo de sus responsables, aunque será lo habitual en el caso de los órganos colegiados cuando este punto sea desarrollado por la legislación autonómica.

\section{CONSIDERACIONES FINALES}

La descuidada regulación de los nuevos «entes» de ámbito territorial inferior al municipio no parece perseguir su proliferación, ni creemos que la desregulación de las entidades de ámbito territorial inferior al municipio vaya a condicionar el funcionamiento de las existentes, porque -como es tradicional en esta materia- se deja en manos de las Comunidades Autónomas definir las características y la capacidad de actuación de ambas formas organizativas.

Lo que resulta difícil de entender es la prohibición de crear nuevas entidades inframunicipales, renunciando de ese modo a un instrumento que se ha empleado con relativo éxito para aliviar o atemperar ten-

ria y sostenibilidad financiera». Y en el apartado cuarto del artículo 11 se dispone que las Corporaciones Locales deben mantener una posición de equilibrio o superávit presupuestario.

${ }^{66}$ Vid. GALÁN y GALINDO (2015: 92), que reflejan las posiciones de los Gobiernos de las Comunidades Autónomas ante la reforma.

${ }^{67}$ Como ha recordado el Tribunal Constitucional, la configuración de estos entes como estructuras desconcentradas supone, de un lado, que el Ayuntamiento se erige en el centro de imputación de las obligaciones y los derechos dimanantes de la actividad de estas «formas de organización desconcentrada» y, de otro, que los órganos municipales de gobierno se relacionan con estas en términos de jerarquía, todo ello sobre la base de que así podrá facilitarse el cumplimiento de los objetivos de eficiencia, eficacia y estabilidad presupuestaria (artículos 31.2, 103.1 y $135 \mathrm{CE}$ ). 
siones segregacionistas y que también podría servir para facilitar las fusiones de municipios ${ }^{68}$. Para evitar el crecimiento incontrolado de este tipo de entidades habría bastado con la introducción con carácter básico de requisitos de eficiencia y sostenibilidad para su constitución.

En relación con los órganos desconcentrados, solo una decidida política autonómica puede favorecer su utilización. Al menos es lo que parece indicar la reducidísima implantación de otras fórmulas de desconcentración municipal, a las que en su momento tampoco se prestó suficiente atención. Nada impedía, por ejemplo, que los Parlamentos Autonómicos configurasen órganos desconcentrados más potentes, puesto que el artículo 24 LBRL no imponía condiciones relevantes; ni a los núcleos de población separados servirse de las formas organizativas existentes antes de la entrada en vigor de la LRSAL. Sin embargo, estos últimos han preferido seguir la vía de la descentralización en las variedades abiertas por la legislación autonómica, todas ellas con personalidad, competencias y patrimonio propios ${ }^{69}$.

La intención del legislador estatal ha sido cerrar esa vía, encauzando cualquier nueva iniciativa hacia soluciones desconcentradas, al mismo tiempo que se endurecían las condiciones para la supervivencia de las entidades existentes y los requisitos para su acceso a la condición de municipio. Sin embargo, los más de tres años de vigencia de la LRSAL parecen confirmar que la reforma está lejos de alcanzar sus objetivos y que todo seguirá igual, al menos hasta que no disminuyan las resistencias autonómicas y locales a su plena aplicación.

Tampoco se puede afirmar que la solución organizativa ideada haya servido para enfriar los ánimos de quienes aspiraban a un mayor nivel de autogobierno. Cabría incluso apuntar que su promulgación ha provocado algunos efectos contrarios a los objetivos perseguidos. Es evidente que las Comunidades Autónomas no se precipitaron a modificar su legislación de régimen local para adaptarla a los fines y exigencias de la LRSAL, sino todo lo contrario (ARROYO YANES, 2014; CASARES MARCOS, 2014; MARTÍNEZ GUTIÉRREZ, 2014; GALÁN GALÁN, 2015; TEJEDOR BIELSA, 2015). Ya adelantamos que, si la legislación autonómica no configura los entes de ámbito territorial inferior al municipio con amplias atribuciones, financiación suficiente y una organización representativa de los vecinos del núcleo separado, no tendrán atractivo como órganos de participación y gestión de los intereses vecinales, por lo que no servirán para aliviar las tensiones segregacionistas que esta ley parece olvidar, a pesar del auge que han adquirido en las últimas décadas.

Debe recordarse que la creación de entidades inframunicipales en los años anteriores a la entrada en vigor de la LRSAL no sirvió en realidad para canalizar los intereses patrimoniales de los poblados rurales o como formas tradicionales de convivencia y asentamiento, que era la finalidad que originariamente justificaba la existencia de entidades locales menores. Desde los años noventa la razón que impulsó la creación de nuevas entidades de ámbito territorial inferior al municipio era el deseo de autogobierno de la población de núcleos que habían crecido demográfica y económicamente, muchas veces superando a la capitalidad municipal ${ }^{70}$. Esas iniciativas además se planteaban la creación de la entidad inframunicipal como un primer paso en un proceso que tenía como objetivo último la segregación del municipio. Por ello, cualquier ente desconcentrado que carezca de las notas apuntadas no servirá para dar respuesta a la situación descrita ${ }^{71}$.

Pero es que, además, la desconfianza manifestada en el anteproyecto de LRSAL hacia las entidades inframunicipales y el temor a que se dificultara la creación de nuevos municipios con el endurecimiento de los requisitos exigidos para ello activaron en muchas Comunidades Autónomas un buen número de procedimientos de creación de municipios por segregación de aquellos pueblos que no cumplían (y seguramente no

${ }^{68}$ REBOLLO PUIG (2009: 168-170) describe como esta posibilidad está prevista en el artículo 41 del Real Decreto 1690/1986, de 11 de julio, por el que se aprueba el Reglamento de Población y Demarcación Territorial de las Entidades Locales, que permitía la transformación de los municipios extinguidos por fusión o incorporación en entidades de ámbito territorial inferior al municipio, permitiéndoles conservar cierto grado de administración de sus propios asuntos como entidades descentralizadas. Y los ejemplos se multiplican en la legislación autonómica. Esta posibilidad pierde parte de su atractivo si, como consecuencia de la LRSAL, ahora solo cabe admitir su transformación en simples órganos desconcentrados.

${ }^{69}$ COSCULLUELA MONTANER duda que las demandas de los vecinos de esos núcleos separados puedan ser cubiertas por fórmulas de gestión desconcentrada, que nacieron en un contexto urbano, para dar respuesta a necesidades de los grandes núcleos de población completamente distintas a las de los núcleos rurales y completamente ajenas a su tradición. Cfr. Prólogo al libro de PIZARRO NEVADO, Rafael (2002), Las entidades de ámbito territorial inferior al municipio: 17. Granada: CEMCI.

70 Vid. REBOLLO PUIG, Manuel y PIZARRO NEVADO, Rafael (2001): “Las Entidades Locales Autónomas”, Administración de Andalucía: Revista Andaluza de Administración Pública, 42: 59-94; y GALÁN y GALINDO (2015: 54).

71 Es indicativo de esto lo sucedido en Andalucía, donde se regularon dos modalidades de entidades descentralizadas: las entidades locales autónomas y las entidades vecinales. Tanto unas como otras tienen personalidad jurídica, pero las segundas solo ejercen competencias municipales delegadas, ninguna propia. Tras una década de vigencia de la LAULA existen en Andalucía 42 entidades locales autónomas (aunque en 2013 eran 47) y, sin embargo, no se ha creado una sola entidad vecinal. 
podrían cumplir tampoco en un futuro cercano) los requisitos previstos en el anteproyecto ${ }^{72}$. Como ejemplo puede señalarse lo sucedido en Andalucía, donde durante el año 2013 se iniciaron al menos quince procedimientos de segregación de entidades locales autónomas de sus municipios matrices, todas ellas con una población sensiblemente inferior a 2.000 habitantes, de los cuales siete han culminado con la creación de nuevos municipios por segregación ${ }^{73}$. Los restantes procedimientos siguen su tramitación, por lo que ni siquiera cabe descartar que ese número aumente en el futuro.

Diferente es el caso de la creación del municipio de Medinyà -con una población de 866 habitantespor segregación del municipio al que previamente había sido agregado en 1972, puesto que la segregación se ha realizado en este caso por Ley del Parlamento de Cataluña 8/2015, de 10 de junio, cuando ya estaba plenamente en vigor la LRSAL. En la exposición de motivos de la Ley catalana se justifica tan peculiar modo de actuar porque así se quería «reparar una decisión antidemocrática, corregir disfuncionalidades y atender a la voluntad de la mayoría de la población», reconociéndose a continuación que se recurre a una ley singular para hacer lo que al Consejo de Gobierno le está vedado por la legislación vigente. Expresivamente se indica en el apartado III de la exposición de motivos: «Bajo el punto de vista formal, dado que la normativa impide que Medinyà se constituya como municipio independiente, se requiere una ley singular que habilite la excepcionalidad de la norma general, que impide la constitución de municipios nuevos cuando no cumplen todos los requisitos legalmente establecidos». Se eluden así, sin empacho alguno, las exigencias del artículo 15 TRLMRLC, y también, no puede olvidarse, las del artículo 13 LBRL, en la redacción vigente desde el 31 de diciembre de 2013. Al no prosperar las negociaciones para resolver las discrepancias competenciales en el seno de la Comisión Bilateral Generalitat-Estado ${ }^{74}$ (artículo 33.2 de la Ley Orgánica 2/1979, de 3 de octubre) se planteó el recurso de inconstitucionalidad número 1401-2016, promovido por el Presidente del Gobierno, contra la Ley de Cataluña 8/2015, de 10 de junio, de creación del municipio de Medinyá. De acuerdo con la doctrina expuesta, el TC ha declarado inconstitucional y nula la Ley del Parlamento de Cataluña 8/2015, de 10 de junio, de creación del municipio de Medinyà en sentencia 108/2017, de 21 de septiembre, por vulnerar las bases del régimen local que corresponde fijar al Estado, entre las que se incluye la determinación de los requisitos necesarios para la constitución de un nuevo municipio (STC 214/1989, de 21 de diciembre); bases que «delimitan el ámbito de actuación de la Comunidad Autónoma y, por tanto, también de su legislador» (FJ 3). Conociendo la doctrina constitucional era fácil prever el sentido del fallo. Lo que no resultará sencillo es dar respuesta a la situación social y política que deriva de sus efectos y a las eventuales resistencias a la ejecución material de la sentencia.

Pero sobre todo lo que reflejan las situaciones descritas son las carencias de los instrumentos previstos en la LBRL para encauzar las tensiones que sufre la planta local y la inaplazable necesidad de alcanzar un acuerdo político que configure mecanismos flexibles que contribuyan a su reducción. Entre ellos, necesariamente deben incluirse vías para satisfacer las inevitables demandas de participación real de los habitantes de los pequeños núcleos de población en la gestión de sus intereses vecinales, para atender sus necesidades y aspiraciones, lo que sin duda puede lograrse sin renunciar al estricto cumplimiento de los principios de eficacia, estabilidad presupuestaria y sostenibilidad financiera. Pero sí conviene abandonar pronto la idea simplista de que los problemas de las Entidades Locales se resolverán suprimiendo los pequeños municipios y las entidades locales menores, porque esa medida no cambiará la realidad, que no es otra que la existencia de pueblos pequeños y alejados de otros, con los condicionantes geográficos, económicos y sociales que de ello se derivan, que no van a desaparecer porque se les niegue la condición de entidades locales. Esa ecuación no se resuelve con respuestas simples, ni rápidas. Al contrario, precisa de soluciones

72 En el apartado segundo del artículo 13 LBRL, en la redacción dada por la LRSAL, se dispone que «la creación de nuevos municipios solo podrá realizarse sobre la base de núcleos de población territorialmente diferenciados, de al menos 5.000 habitantes y siempre que los municipios resultantes sean financieramente sostenibles, cuenten con recursos suficientes para el cumplimiento de las competencias municipales y no suponga disminución en la calidad de los servicios que venían siendo prestados». Sobre la nueva regulación del artículo 13 LRBL vid. ALMEIDA CERREDA, Marcos (2014: 7-26); COSCULLUELA MONTANER, Luis (2013): "Reforma de la Administración Local. Una oportunidad de modificar la planta municipal que no puede perderse”, Revista Española de Derecho Administrativo, 157: 11-19.

73 En 2014 se crearon los municipios de Dehesas Viejas y Valderrubio en Granada, y en 2015 fueron los de Montecorto y Serrato en Málaga, Balanegra en Almería y Játar y Domingo Pérez en Granada (2015). No han sido las únicas entidades de ámbito territorial inferior al municipio que se han segregado para constituir nuevos municipios. También pueden citarse la segregación de Tiétar (2013) y Pueblonuevo de Miramontes (2015), ambos en Cáceres.

74 En reunión celebrada el día 16 de julio de 2015 la Subcomisión de Seguimiento Normativo, Prevención y Solución de Conflictos de la citada Comisión Bilateral acordó iniciar negociaciones para resolver las discrepancias competenciales suscitadas en relación con la Ley de Cataluña 8/2015, de 10 de junio, de creación del municipio de Medinyà. 
REALA. Nueva Época - N. 8, noviembre 2017 - ISSN: 1989-8975 - DOI: 10.24965/reala.v0i8.10437 - [Págs. 49-73]

Entidades y «entes» de ámbito territorial inferior al municipio tras la reforma local de 2013

Rafael Pizarro Nevado

inteligentes, duraderas, consensuadas entre los distintos poderes territoriales y, sobre todo, adaptadas a la realidad física, social y cultural de las poblaciones afectadas.

\section{REFERENCIAS BIBLIOGRÁFICAS}

AEPDA (edit., 2013): La planta del gobierno local: actas del VIII Congreso de la Asociación Española de Profesores de Derecho Administrativo, Barcelona: Fundación Democracia y Gobierno Local.

ALMEIDA CERREDA, Marcos (2014): "La planta local a pequeña escala: municipios y entidades locales menores", Cuadernos de Derecho Local, 35: 7-26.

ALMEIDA CERREDA, Marcos (2015): "Tres procesos contemporáneos de reforma de las organizaciones administrativas locales: orígenes, finalidades y líneas de actuación coincidentes”, en La racionalización de la organización administrativa local: las experiencias española, italiana y portuguesa, 29-44. Madrid: Civitas.

ALMEIDA CERREDA, Marcos (2016): "La incidencia de la sentencia del Tribunal Constitucional 41/2016, sobre la reforma del régimen de las entidades locales menores efectuada por la Ley 27/2013", en BATALHÃO, Carlos José (coord.): As Freguesias na Organização do Estado - Um Património Nacional: 233-249. Lisboa: ANAFRE Associação Nacional de Freguesias.

AMENÓS ALAMO, Joan (2014), "El elemento territorial del municipio en la Ley 27/2013, de Racionalización y Sostenibilidad de la Administración Local”, Anuario del Gobierno Local 2013. Barcelona: Fundación Democracia y Gobierno Local - Instituto de Derecho Público.

ARROYO YANES, Luis Miguel (2014): "El impacto de la reforma de la LRBRL en la Comunidad Valenciana", en QUINTANA LÓPEZ, Tomás (dir.) y CASARES MARCOS, Ana Belén (coord.): La reforma del régimen local: 923963. Valencia: Tirant lo Blanch.

BAZAKO ATUTXA, Peru y ETXANOBE LANDAJUELA, Elixabete (2015): “Ley Municipal de Euskadi. ¿Esta vez sí?”, Revista Vasca de Gestión de Personas y Organizaciones Públicas, 8: 66-85.

BOIX PALOP, Andrés (2014): "Sentido y orientación de la Ley 27/2013 de racionalización y sostenibilidad de la Administración local: autonomía local, recentralización y provisión de servicios públicos locales”, Revista de Estudios de la Administración Local y Autonómica. Nueva época, 2. DOI: 10.24965/reala.v0i2.10199.

BOIX PALOP, Andrés (2017): "El régimen local tras el fracaso de la reforma 2013", El cronista del Estado Social y Democrático de Derecho, 68: 24-35.

BOIX PALOP, Andrés y DE LA ENCARNACIÓN, Ana María (coord., 2015): Los retos del gobierno local tras la reforma de 2013: 81-100. Cizur Menor (Navarra): Thomson Reuters-Aranzadi.

CARBONELL PORRAS, Eloísa (2014): "Sobre la reforma local y las competencias municipales propias", Revista Vasca de Administración Pública, núm. especial 99-100: 765-781.

CASARES MARCOS, Ana Belén (2014): "Régimen local y prestación de servicios públicos en Castilla y León tras la aprobación de la Ley autonómica 7/2013, de 27 de septiembre, y la LRSAL”, en QUINTANA LÓPEZ, Tomás (dir.) y CASARES MARCOS, Ana Belén (coord.): La reforma del régimen local: 769-853. Valencia: Tirant lo Blanch.

CASTRO BERMEJO, Cristina (1998): "Marco jurídico de la parroquia rural en Galicia", Revista de Estudios de la Administración Local y Autonómica, 276: 179-202. DOI: 10.24965/reala.vi276.8980.

COSCULLUELA MONTANER, Luis (1978): voz "Junta Vecinal”, en Nueva Enciclopedia Jurídica Seix, Tomo XIV. Barcelona.

COSCULLUELA MONTANER, Luis (2013): "Reforma de la Administración Local. Una oportunidad de modificar la planta municipal que no puede perderse", Revista Española de Derecho Administrativo, 157: 11-19.

DOMINGO ZABALLOS, Manuel José (coord., 2014): Reforma del Régimen Local. La Ley de Racionalización y Sostenibilidad de la Administración Local: veintitrés estudios. Cizur Menor (Navarra): Thomson Reuters-Aranzadi.

FARIÑA JAMARDO, José (1981): La parroquia rural en Galicia, 2. a edición. Madrid.

FONT i LLOVET, Tomás y GALÁN GALÁN, Alfredo (2013), "Racionalización y sostenibilidad de la Administración local: ¿es ésta la reforma?" Anuario del Gobierno Local 2012, Barcelona: Fundación Democracia y Gobierno Local Instituto de Derecho Público.

FONT I LLOVET, Tomás y GALÁN GALÁN, Alfredo (2014): “La reordenación de las competencias municipales: ¿una mutación constitucional?", Anuario del Gobierno Local 2013. Barcelona: Fundación Democracia y Gobierno Local - Instituto de Derecho Público.

GALÁN GALÁN, Alfredo (2015): "La aplicación autonómica de la Ley de Racionalización y Sostenibilidad de la Administración Local”, Revista de Estudios de la Administración Local y Autonómica: Nueva Época, núm. extra 1. DOI: $10.24965 /$ reala.v0iextra.10225.

GALÁN GALÁN, Alfredo y GALINDO CALDÉS, Ramón (2015): “Las entidades de ámbito territorial inferior al municipio", en La racionalización de la organización administrativa local: las experiencias española, italiana y portuguesa: 47103. Madrid: Civitas.

GALINDO CALDÉS, Ramón Lluís (2014): La organización territorial en los municipios: los distritos. Granada: CEMCIDiputación de Granada. 
REALA. Nueva Época - N. 8, noviembre 2017 - ISSN: 1989-8975 - DOI: 10.24965/reala.v0i8.10437 - [Págs. 49-73]

Entidades y «entes» de ámbito territorial inferior al municipio tras la reforma local de 2013

Rafael Pizarro Nevado

MARTÍNEZ GUTIÉRREZ, Rubén (2014): "El impacto de la reforma de la LRBRL en la Comunidad Valenciana", en QUINTANA LÓPEZ, Tomás (dir.) y CASARES MARCOS, Ana Belén (coord.): La reforma del régimen local: 855921. Valencia: Tirant lo Blanch.

MEDINA ALCOZ, Luis (2017): “'La distribución de competencias entre el Estado y las comunidades autónomas a la luz de las sentencias constitucionales sobre la reforma local de 2013", Anuario del Gobierno Local 2015/2016. Barcelona: Fundación Democracia y Gobierno Local - Instituto de Derecho Público.

MEDINA GUERRERO, Manuel (2014), La reforma del régimen local. Valencia: Tirant lo Blanch.

MENÉNDEZ GARCÍA, Pablo (2003): "Las entidades de ámbito territorial inferior al municipio", en MUÑOZ MACHADO, Santiago (dir.): Tratado de Derecho Municipal, Tomo I: 1179-1208. Madrid: Civitas.

MELLADO RUIZ, Lorenzo (2014a): "Consecuencias derivadas de la supresión del principio de mayor proximidad”, El Consultor de los Ayuntamientos y de los Juzgados, 5.

MELLADO RUIZ, Lorenzo (2014b): Génesis y realidad de la Ley 27/2013, de 27 de diciembre, de Racionalización y Sostenibilidad de la Administración Local: ¿una nueva reforma económica local? Granada: CEMCl.

MíGUEZ MACHO, Luis (2013): "Galicia y la reforma de la Administración local", Dereito: Revista xuridica da Universidade de Santiago de Compostela, núm. extra 1, 319-336.

ORDUÑA REBOLLO, Enrique (2000): "Las entidades de ámbito territorial inferior al municipio. Del pasado al futuro", en SOSA WAGNER, Francisco (coord.): El Derecho Administrativo en el umbral del siglo XXI. Homenaje al Dr. D. Ramón Martín Mateo, Tomo I: 745-772. Valencia: Tirant lo Blanch.

PIZARRO NEVADO, Rafael (2002), Las entidades de ámbito territorial inferior al municipio. Granada: CEMCI.

PIZARRO NEVADO, Rafael (2007): "Comentario al artículo 45 LBRL", en REBOLLO PUIG, Manuel (dir.): Comentarios a la Ley Reguladora de las Bases de Régimen Local: 1053-1087. Valencia: Tirant lo Blanch.

QUINTANA LÓPEZ, Tomás (1991): "La desconcentración en la organización de los Municipios”, Documentación administrativa, 228: 145-166.

QUINTANA LÓPEZ, Tomás (dir.) y CASARES MARCOS, Ana Belén (coord., 2014): La reforma del régimen local. Valencia: Tirant lo Blanch.

RAZQUIN LIZARRAGA, Martín María (2014): "Reforma local y derechos históricos: Navarra y País Vasco", en DOMINGO ZABALLOS, Manuel José (coord.): Reforma del Régimen Local. La Ley de Racionalización y Sostenibilidad de la Administración Local: veintitrés estudios: 117-150. Cizur Menor (Navarra): Thomson Reuters-Aranzadi.

REBOLLO PUIG, Manuel (2009): "La supresión de los pequeños municipios: régimen, alternativas, ventajas e inconvenientes", Revista de Estudios de la Administración Local y Autonómica, 308: 151-205. DOI: 10.24965/ reala.v0i308.9701.

REBOLLO PUIG, Manuel y PIZARRO NEVADO, Rafael (2001): “Las Entidades Locales Autónomas”, Administración de Andalucía: Revista Andaluza de Administración Pública, 42: 59-94.

ROSA MORENO, Juan (1991): "Aproximación histórica a la articulación orgánica de los núcleos separados de población", Revista de Estudios Locales y Autonómicos, 262: 219-246. DOI: 10.24965/reala.vi262.8823.

SANTAMARÍA PASTOR, Juan Alfonso (coord., 2014): La reforma de 2013 del régimen local español. Barcelona: Fundación Democracia y Gobierno Local.

TEJEDOR BIELSA, Julio (2015): "El desarrollo autonómico de la reforma local de 2013. Entre la rebelión y el pragmatismo”, en BOIX PALOP, Andrés y DE LA ENCARNACIÓN, Ana María (coord.): Los retos del gobierno local tras la reforma de 2013: 81-100. Cizur Menor (Navarra): Thomson Reuters-Aranzadi.

TOLIVAR ALAS, Leopoldo (2014): "Las entidades inframunicipales", La reforma del régimen local. Comentario a la Ley 27/2013, de 27 de diciembre, de Racionalización y Sostenibilidad de la Administración Local: 371-403. Valencia: Tirant lo Blanch.

TRAYTER JIMÉNEZ, Joan Manuel (2007): “Comentario a los artículos 24 y 128 LBRL”, en REBOLLO PUIG, Manuel (dir.): Comentarios a la Ley Reguladora de las Bases de Régimen Local: 671-681. Valencia: Tirant lo Blanch.

VELASCO CABALLERO, Francisco (2013a): "Sobre el dictamen del Consejo de Estado en relación con el Anteproyecto de Ley de Racionalización y Sostenibilidad de la Administración Local”, Boletín del Instituto de Derecho Local de la Universidad Autónoma de Madrid, 46 [Disponible en: http://www.idluam.org/images/files/boletines/BOLETIN_46_ index_archivos/Page426.htm. Fecha de última consulta: 1 de julio de 2017].

VELASCO CABALLERO, Francisco (2013b), "Títulos competenciales y garantía constitucional de autonomía local en la Ley de Racionalización y Sostenibilidad de la Administración Local”, en SANTAMARÍA PASTOR, Juan Alfonso (coord.), La reforma de 2013 del régimen local español: 75-136. Madrid: Fundación Democracia y Gobierno Local.

VELASCO CABALLERO, Francisco (2014a): "Sobre la aplicación de la LRSAL en el País Vasco: el alcance de las cláusulas de excepción”, Blog del Instituto de Derecho Local de la Universidad Autónoma de Madrid [Disponible en: http://www.idluam.es/actualidad/6422-estudios-doctrinales-sobre-la-aplicacion-\%20de-la-Irsal-en-el-paisvasco-el-alcance-de-las-clausulas-de-excepcion. Fecha de última consulta: 1 de junio de 2016].

VELASCO CABALLERO, Francisco (2014b): "La ley de racionalización y sostenibilidad de la Administración local en el sistema de derecho local”, Reforma del Régimen Local. La Ley de Racionalización y Sostenibilidad de la Administración Local: veintitrés estudios: 43-81. Cizur Menor: Aranzadi.

VELASCO CABALLERO, Francisco (2014c): "El nuevo régimen local general y su aplicación diferenciada en las distintas comunidades autónomas", Revista catalana de dret públic, 48: 1-23. DOI: 10.2436/20.8030.01.18. 